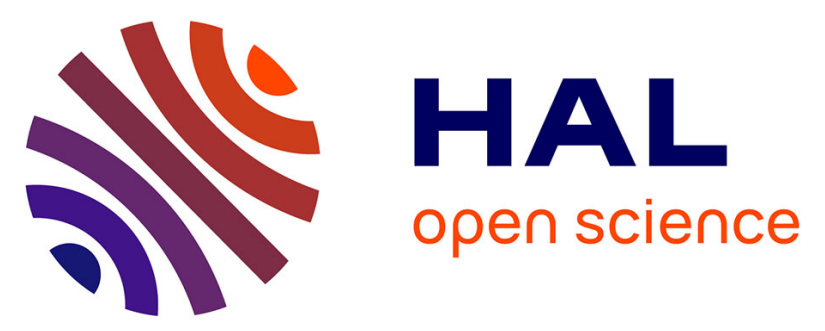

\title{
How the truffle got its mate: insights from genetic structure in spontaneous and planted Mediterranean populations of Tuber melanosporum
}

Elisa Taschen, F. Rousset, M. Sauve, L. Benoit, M.-P. Dubois, F. Richard, M.-A. Selosse

\section{To cite this version:}

Elisa Taschen, F. Rousset, M. Sauve, L. Benoit, M.-P. Dubois, et al.. How the truffle got its mate: insights from genetic structure in spontaneous and planted Mediterranean populations of Tuber melanosporum. Molecular Ecology, 2016, 25 (22), pp.5611-5627. 10.1111/mec.13864 . hal-01395118

\section{HAL Id: hal-01395118 https://hal.sorbonne-universite.fr/hal-01395118}

Submitted on 10 Nov 2016

HAL is a multi-disciplinary open access archive for the deposit and dissemination of scientific research documents, whether they are published or not. The documents may come from teaching and research institutions in France or abroad, or from public or private research centers.
L'archive ouverte pluridisciplinaire HAL, est destinée au dépôt et à la diffusion de documents scientifiques de niveau recherche, publiés ou non, émanant des établissements d'enseignement et de recherche français ou étrangers, des laboratoires publics ou privés.

$$
\text { Copyright }
$$


Received Date : 21-Dec-2015

Revised Date : 17-Sep-2016

Accepted Date : 19-Sep-2016

Article type : Original Article

How the truffle got its mate: insights from genetic structure in spontaneous and planted

Mediterranean populations of Tuber melanosporum.

TASCHEN E. ${ }^{1,2,}$, ROUSSET F. ${ }^{3}$, SAUVE M. ${ }^{1}$, BENOIT L. ${ }^{1}$, DUBOIS M.-P. ${ }^{1}$, RICHARD F. ${ }^{1}$, SELOSSE M.-A. ${ }^{2,4}$

${ }^{1}$ CEFE UMR 5175, CNRS - Université de Montpellier - Université Paul-Valéry Montpellier - EPHE 1919 route de Mende, 34293 Montpellier, France.

${ }^{2}$ Institut de Systématique, Évolution, Biodiversité (ISYEB - UMR 7205 - CNRS, MNHN, UPMC, EPHE), Muséum national d'Histoire naturelle, Sorbonne Universités, 57 rue Cuvier (CP50), 75005, Paris, France

${ }^{3}$ Institut des Sciences de l'Evolution, Université de Montpellier, CNRS, IRD, EPHE CC 065; Place Eugène Bataillon, 34095 Montpellier cedex 05, France.

○ corresponding author. Email: elisa.taschen@outlook.com

Running title: Mating and diversity in Tuber melanosporum

This article has been accepted for publication and undergone full peer review but has not been through the copyediting, typesetting, pagination and proofreading process, which may lead to differences between this version and the Version of Record. Please cite this article as 


\section{Summary.}

The life cycles and dispersal of edible fungi are still poorly known, thus limiting our understanding of their evolution and domestication. The prized Tuber melanosporum produces fruitbodies (fleshy organs where meiospores mature) gathered in natural, spontaneously inoculated forests or harvested in plantations of nursery-inoculated trees. Yet, how fruitbodies are formed remains unclear, thus limiting yields, and how current domestication attempts affect population genetic structure is overlooked. Fruitbodies result from mating between two haploid individuals: the maternal parent forms the flesh and the meiospores, while the paternal parent only contributes to the meiospores. We analyzed the genetic diversity of $T$. melanosporum comparatively in spontaneous forests versus plantations, using SSR polymorphism of 950 samples from South-East France. All populations displayed strong genetic isolation by distance at the metric scale, possibly due to animal dispersal, meiospore persistence in soil, and/or exclusion of unrelated individuals by vegetative incompatibility. High inbreeding was consistently found, suggesting that parents often develop from meiospores produced by the same fruitbody. Unlike maternal genotypes, paternal mycelia contributed to few fruitbodies each, did not persist over years, and were undetectable on tree mycorrhizae. Thus, we postulate that germlings from the soil spore bank act as paternal partners. Paternal genetic diversity and outbreeding were higher in plantations than in spontaneous truffle-grounds, perhaps because truffle growers disperse fruitbodies to maintain inoculation in plantations. However, planted and spontaneous populations were not genetically isolated, so that $T$. melanosporum illustrates an early step of domestication where genetic structure remains little affected.

Keywords: Dispersal; Domestication; Ectomycorrhizae; Hermaphroditism; Hypogeous fungi; Inbreeding 


\section{Introduction}

Edible mushrooms are of major economic interest, and although many saprotrophic fungi are now routinely cultivated (Chang \& Hayes 2013, Cheeseman et al. 2014), the cultivation of most species remains challenging because we hardly control their sexual reproduction, which produces edible fruitbodies. Many edible and prized forest fungi cannot be cultivated, such as mycorrhizal fungi, and thus still escape domestication (a process in which reproduction is controlled; Murphy 2007). These fungi form root symbioses on trees, establishing a dual organ called an ectomycorrhiza (van der Heijden et al. 2015), and comprise more than 1000 edible species worldwide, including delicacies such as truffles, chanterelles and porcini (Zambonelli \& Bonito 2012). They are mostly harvested wild in forests, where their propagation is sometimes favoured, but not fully controlled, by forest management and/or inoculation practices (e.g., El Karkouri et al. 2006; de Miguel et al. 2014). They thus undergo an early stage of domestication, hereafter called proto-domestication (Zeder 2008).

Our imperfect knowledge of the reproduction and population genetics of mycorrhizal fungi limits their optimal use and the development of associated cultural practices (Zambonelli \& Bonito 2012). Here we focus on the prized black truffle (Tuber melanosporum Vittad, an Ascomycota). It is harvested at natural sites, where trees and T. melanosporum occur spontaneously, and at managed sites, where trees are inoculated by truffle fruitbodies (Callot 1999; Murat 2014), first in the nursery, and later in the field where fruitbody fragments are periodically scattered on the soil in an empirical attempt to 're-inoculate' trees (Callot 1999). The latter plantations have existed since the 19th century (Chatin 1869; Hall et al. 2008) and now account for $80 \%$ of the harvest (Murat 2014). We can thus distinguish two extremes: sites where trees and T. melanosporum occur spontaneously versus sites with inoculated trees (respectively, spontaneous truffle-grounds versus plantations). Genetic differentiation and differences in genetic structure between these compartments remain unclear. Inoculation treatments may modify dispersal, normally vectored by truffle-eating animals (Hochberg et al. 2003; Piattoni et al. 2014; Fig. 1). Although tree inoculations can enhance genetic diversity at 
the local scale due to the use of more mixed inoculum, the whole diversity and outbreeding level in plantations may be reduced due to a bottleneck (as in crop species; Glémin \& Bataillon 2009; Miller \& Gross 2011) linked to a restricted origin of inocula. Moreover, we anticipate a less pronounced isolation by distance (IBD) among planted truffle-grounds at the regional scale due to commercial exchange of inoculated seedlings.

Other unclear aspects of the genetic dynamics and reproduction of T. melanosporum limit our ability to domesticate T. melanosporum (Selosse et al. 2013; Le Tacon et al. 2015). Population genetics studies of mycorrhizal fungi have focused on Basidiomycota (see Douhan et al. 2011 for review), and have neglected mycorrhizal Ascomycota, which are diverse (Tedersoo et al. 2006; Healy et al. 2013). Ascomycota, including T. melanosporum, differ from Basidiomycota by a haploid vegetative life (Korf 1973; Debuchy et al. 2010; Figs. 1 and S1). In particular, their fruitbody, where a diploid zygote is formed and meiotic spores (the ascospores) are matured, results from the mating between two haploid individuals (Guidot et al. 2003; Douhan et al. 2011). Indeed, a mating-type locus with two alleles prevents haploid self-fertilization (Rubini et al. 2011ab; Billiard et al. 2012). In T. melanosporum, simple sequence repeat [SSR] analysis has revealed that one haploid individual produces the fruitbody flesh (Figs. 1 and S1), while specific DNA extraction from ascospores (Rubini et al. 2011b) showed that the other exclusively contributes to the diploid zygote from which ascospores derive by meiosis (Fig. 1). The first parent forms mycorrhizae on nearby trees (Rubini et al. 2011a; Murat et al. 2013), feeds the fruitbody (Le Tacon et al. 2013), and is thus considered maternal, while the second one is considered paternal. Yet any individual can behave maternally or paternally, since, as in many related Ascomycota species (Korf 1973), each haploid T. melanosporum is potentially hermaphroditic (Le Tacon et al. 2015).

At least two aspects of mating remain obscure: firstly, the extent of biparental inbreeding, i.e. the relatedness between parents of a fruitbody, and, secondly, the physical location of fathers relative 
to their offspring fruitbodies. So far, paternal individuals have not yet been found on nearby mycorrhizae (Rubini et al. 2011a). Ascomycota display various fertilization mechanisms (Korf 1973; Debuchy et al. 2010; Selosse et al. 2013), ranging from direct contact between nearby mycelia to distant fertilization by dispersal of passively mobile gametes: spermatia (Fig. S1), which can contribute to gene dispersal (Guidot et al. 2003; Healy et al. 2013), are reported in some Tuber species (Urban et al. 2004), but not yet for T. melanosporum.

Finally, the vegetative stage also raises questions. Tuber melanosporum develops in patches around host trees where herbaceous plants grow poorly, the brûlés (Streiblová et al. 2012). In brûlés, several maternal haploid mycelia of metric size produce up to a dozen fruitbodies per year (Murat et al. 2013). Maternal genotypes of fruitbodies display a strong IBD on the scale of brûlés (<5 m; Murat et al. 2013) or plantations (<100 m; Bertault et al. 2001). Moreover, spatially close genets seem to carry the same mating type (Rubini et al. 2011a; Zampieri et al. 2012; Murat et al. 2013), likely due to progressive elimination of the other mating types during population establishment (Rubini et al. 2011a). However, there is so far limited statistical support for this poorly understood mating type aggregation, and its impact on inbreeding or on mating limitation is still debated (Linde \& Selmes 2012; Zampieri et al. 2012; Selosse et al. 2013; Rubini et al. 2014). Finally, these spatial structures have been little studied in spontaneous truffle-grounds.

To understand the spatial genetic structure and mode of reproduction of a mycorrhizal Ascomycota, and to evaluate how current proto-domestication attempts affect them, we investigated three main questions concerning T. melanosporum population biology (Fig. 1) in plantations and spontaneous truffle-grounds. [1] First, what is extent of gene flow and spatial genetic structure in $T$. melanosporum, based on analysis of IBD and on mating-type aggregation? [2] Second, what is the level of inbreeding in zygotes and, from the vegetative distribution of parental genets around fruitbodies, is there gene dispersion by male gametes? Finally, [3] do spontaneous and planted compartments differ in these features of the life cycle ([1] and [2]), and are they genetically isolated 
from each other? To answer these questions, we used a large sampling of fruitbodies and mycorrhizae at three scales (brûlé, truffle-ground, and regional; Table 1) in plantations and spontaneous truffle-grounds in Southern France.

\section{Materials and Methods}

\section{Study sites, scales of study and fruitbody sampling}

Fruitbodies from spontaneous truffle-grounds and plantations were sampled by trained dogs on the brûlé, truffle-ground and regional scales (Table 1) in South-East France (located in Fig. S2). For homogeneity, we restricted our sampling to truffle-grounds where the soil is irrigated and trees are pruned, which are usual practices in France. Inoculation and tree origin differ as described above: they are natural in spontaneous truffle-grounds, while plantations (i) are established by trees planted after nursery inoculation by mixing several fruitbodies into the potting mix, and (ii) receive, at least for all those sampled at the brûlé scale, recurrent dispersal of fresh fruitbody fragments on the soil in late winter (which never occurred on our spontaneous truffle-grounds). For simplicity, a brûlé under a planted tree is hereafter called a 'planted brûlé'. Trees of all sites have different ages, due to spontaneous regeneration or replacement of dead planted trees. Our sampling was performed at three scales (Table 1).

At the brûlé scale, harvested fruitbodies were mapped and sampled (Fig. 2 and S3) from 2010 to 2014 on two spontaneous brûlés at Pezilla-de-Conflent (site SB1, under Quercus pubescens) and Tourbes (SB2, under Quercus ilex) and from two planted brûlés, PB1 and PB2, each under $Q$. pubescens, $2 \mathrm{~km}$ away from each other near Nant (see geographic positions in Table 1). Four more brûlés selected in the first instance did not produce enough fruitbodies for our study. We thus reused freeze-dried fruitbodies from a planted brûlé at Viols-le-Fort (PB3) collected from 1995 to 1997 by Bertault et al. (2001). 
At the truffle-ground scale, harvested fruitbodies were mapped (Table 1 and Fig. S4) from 2010 to 2014 on two spontaneous truffle-grounds at Montaren-St-Médiers (SG1) and Le Beaucet (SG2), and fragments $\left(0.5 \mathrm{~cm}^{3}\right.$ per fruitbody) were sampled. We also genotyped fruitbodies from a plantation at Viols-le-Fort (PG1) freeze-dried by Bertault et al. (2001) from 1995 to 1997. Two other truffle plantations sampled over two years did not produce enough fruitbodies for our study. Finally, for some investigations at this scale, we reanalyzed the data of Murat et al. (2013) from the Rollainville plantation (PG2).

At the regional scale, we supplemented our sampling with fruitbody fragments $\left(0.5 \mathrm{~cm}^{3}\right.$ per fruitbody) from various spontaneous truffle-grounds and plantations (Table 1 and Fig. S2) in a $150 \mathrm{x}$ $400 \mathrm{~km}$ area, extending from Western (Midi-Pyrénées) to Eastern (Provence-Côte d'Azur) Mediterranean France. All samples were stored at $-20^{\circ} \mathrm{C}$ until molecular analysis.

\section{Mycorrhizae sampling}

Tree mycorrhizae (ectomycorrhizae) were sampled on SB1 (Fig. 2) and PB1 (Fig. S3b) in February 2011 under positions of fruitbodies found in 2010-2011, using a $10 \mathrm{~cm}$ wide, $20 \mathrm{~cm}$ long soil corer. Systematic fine-scale mycorrhizae sampling was also performed in July 2011 on two square zones of SB1 $\left(0.5\right.$ and $\left.1 \mathrm{~m}^{2}\right)$, where soil was sampled every $15 \mathrm{~cm}$ with the same corer (Fig. 2). Within two days, roots were washed and investigated under the dissecting microscope, and all mycorrhizae showing morphological evidence of colonization by T. melanosporum (Miguel \& Saez 2005) were recovered and stored at $-20^{\circ} \mathrm{C}$ (Table 1$)$. 


\section{Molecular analyses}

DNA from mycorrhizae and fruitbodies (to obtain maternal DNA from the flesh) was extracted using the RED Extract-N-Amp Kit following the manufacturer's instructions. We also extracted DNA from ascospores to access the zygotic DNA (and to deduce paternal genotypes) based on the protocol of Paolocci et al. (2006); since this method requires much fruitbody material, it was not carried out on fruitbody fragments collected at the truffle-ground and regional scales. Thin fruitbody slices from frozen fruitbodies were cut with a sterile razor blade and recovered in $5 \mathrm{~mL}$ of sterile distilled water in a Petri dish. Asci and ascospores sedimenting in water were placed in $2 \mathrm{~mL}$ tubes, submerged in $80 \mu \mathrm{L}$ of distilled water using a micropipette, and crushed with steel spheres in a BeadBeater (MM301, Retsch, Haan, Germany) for $60 \mathrm{~s}\left(30\right.$ jolts s$\left.{ }^{-1}\right)$. Disruption was checked under the microscope, and DNA from $5 \mu \mathrm{L}$ of crushed-spore suspension was extracted as above. The presence of T. melanosporum on mycorrhizae was tested using the specific primers MelF and MelR as in Douet et al. (2004). On extracts from fruitbodies and mycorrhizae (950 samples in all; Table 1), mating type was typed by PCR amplification using primers p19-p20 and p1-p2 as in Rubini et al. (2011b). For genotyping, fourteen SSR primer sets were selected from Murat et al. (2011) using the criterion of high allelic diversity (Table S1), and PCR reactions were carried out in $5 \mu \mathrm{L}$ of Multiplex Qiagen, $1 \mu \mathrm{L}$ of the multiplexed primer mix $(2 \mu \mathrm{M}), 1 \mu \mathrm{L}$ of Qiagen buffer, $2 \mu \mathrm{L}$ of sterile water and $1 \mu \mathrm{L}$ of DNA extract. PCR was performed in a Mastercycler gradient thermocycler (Eppendorf, Le Pecq, France), with initial denaturation of $15 \mathrm{~min}$ at $95^{\circ} \mathrm{C}, 40$ cycles of denaturation, annealing and elongation respectively at $94^{\circ} \mathrm{C}$ for $30 \mathrm{~s}, 55^{\circ} \mathrm{C}$ for $90 \mathrm{~s}$ and $72^{\circ} \mathrm{C}$ for $90 \mathrm{~s}$, followed by a final extension at $72^{\circ} \mathrm{C}$ for 10 min. The resulting DNA fragments were separated in an ABI PRISM ${ }^{\circledR} 3100$ Genetic Analyzer using 500 LIZ (Life Technology, Carlsbad, USA) as size marker. Note that the Rollainville dataset was based on 10 SSR loci already analyzed in Murat et al. (2013). 


\section{SSR genotype delineation}

For the sampling of this study, SSR profiles were analyzed with GeneMapper ${ }^{\circledR}$ Software (Applied Biosystems, Foster City, CA USA). The marker me09, whose chromatograms were difficult to interpret, was discarded from the analyses. For flesh and mycorrhizae, we first discarded all samples for which more than two loci did not successfully amplify. Second, some flesh extracts $(<10 \%)$ displayed apparent heterozygous genotypes, likely due to contamination by ascospore DNA, and were discarded. In sampling at the brûlé scale (Table 1), zygotic genotypes were only considered when the two mating-type alleles were amplified successfully, a criterion confirming efficient spore DNA extraction. Then, paternal genotypes were obtained by differences from the flesh (maternal) genotype. For inbreeding analyses in brûlé populations (Table 1), all SSR loci were considered for zygotes. For other analyses, we defined haploid multilocus genotypes (MLGs) based on the mating type and SSR loci. To avoid genotyping uncertainties, we further screened SRR data and, considering separately the brûlé and truffle-ground scales, we first discarded: (i) SSR loci with more than 9\% of missing data at the focus scale, resulting in elimination of Tm2 and Tm98 at the brûlé scale, and Tm2 and Tm21 at the truffle-ground scale; and (ii) samples with missing data for one or more SSR loci in the remaining dataset; we obtained one 'MLG dataset' per population. For MLGs represented more than once in fruitbodies and/or mycorrhizae, the probability that the replicate genotypes resulted from independent events of sexual reproduction $\left(P_{\text {sex, }}\right.$ under Hardy-Weinberg linkage equilibrium; Parks \& Werth 1993; Arnaud-Haond \& Belkhir 2007) was calculated using MLGSim.

\section{Biparental inbreeding}

Heterozygote deficits were estimated from the zygotic genotype for the five investigated brûlés

(Table 1). Since parental haploid genotypes are known, the heterozygote deficit test based on Levene's (1949) distribution conditional on observed allelic counts is not appropriate. We instead 
simulated the distribution of samples with random pairing of available parental and maternal MLGs (10000 simulated samples) for each brûlé, using R (R Core Team 2014; script available at http://dx.doi.org/10.5061/dryad.vm11r). The test statistic computed for the original sample (Table 2) and all simulated ones was the score statistic (Raymond \& Rousset 1995), or equivalently Robertson and Hill's (1984) estimator of $F_{I S}$. To compare heterozygote deficit between spontaneous and planted brûlés, the same estimator of $F_{I S}$ was computed for each locus in each brûlé, and its distributions in each of the two compartments (spontaneous versus planted) were compared using a Wilcoxon test.

\section{Interannual persistence of MLGs}

Persistence of genets over years was estimated from the MLG datasets at the brûlé and truffleground scales (Table 1). Correlation between the number of fruitbodies produced or genet size (approximated as the maximal distance between fruitbodies with same MLG), and the number of seasons of fructification of genets was calculated using Spearman's rank correlation test using joint data at the brûlé and truffle-ground scales.

\section{Diversity and spatial structure at the truffle-ground scale}

Diversity indices were calculated for each MLG dataset using GenClone v.2.0 (Arnaud-Haond \& Belkhir 2007). Clonal diversity was measured as $R=(\mathrm{G}-1) /(\mathrm{N}-1)$ according to Dorken \& Eckert (2001), where $N$ is the number of fruitbodies and $G$ the number of MLGs. Simpson's complement index (1-D) was calculated to estimate the probability that two randomly sampled fruitbodies in the population have distinct MLGs. Clonal evenness (ED) was measured as in Fager (1972). To take into account repeated sampling of the same MLG, we created a culled MLG dataset with only one sample per MLG and brûlé, with its virtual spatial MLG position at the isobarycentre of all its fruitbody positions. 
This was used in particular to test for a spatial aggregation of the mating-type alleles by Mantel tests on each truffle-ground (Table 1) with 9999 permutations (Genepop): the significance of the overall hypothesis of aggregation was evaluated using Fisher's combined probability test, combining probabilities from independent tests on each truffle-ground, and comparing the distribution with a Chi-squared distribution with $2 \mathrm{k}$ degrees of freedom (Fisher 1925). Patterns of IBD were studied on culled MLG datasets using the regression of the statistic â, a generalization of $F_{s t} /\left(1-F_{s t}\right)$ between pairs of individuals (Rousset 2000), to the logarithm of distance. In a two-dimensional model of isolation by distance, the inverse of the slope of the regression provides an estimate of the neighbourhood size, $4 \Pi D \sigma^{2}$, where $D$ is the effective density of individuals, and $\sigma^{2}$ is the second moment of the dispersal distance (i.e. the mean squared parent-offspring distance; Rousset 1997). The correlation between genetic and geographic distances was tested by means of a Mantel test (9999 permutations) implemented in Genepop 4.4 (Rousset 2008). To disentangle spatial patterns within and among brûlés, IBD was evaluated at the truffle-ground scale separately over all MLGs and over MLGs belonging to different brûlés only (i.e. excluding pairs of MLGs from same brûlé). Likelihood estimates of neighbourhood size were also obtained using Migraine (Rousset \& Leblois 2007, 2012). These estimates may be more accurate, but they do not allow the analysis of distinct causes of isolation by distance through quantification of patterns within and among brûlés. MLG datasets were also used to test multilocus disequilibrium for each pair of loci on each truffle-ground using Genepop.

\section{Diversity and spatial structure at the regional scale}

Analyses at the regional scale were based on a dataset cumulating: (i) fruitbodies from the supplemental regional sampling, and (ii) one randomly chosen representative fruitbody per maternal MLG from each population sampled at the brûlé and truffle-ground scales (Table 1). We considered all 13 SSR loci to maximize the statistical power, and distinguished samples from planted and 
spontaneous compartments. Genetic diversity in each compartment was described by the total number of alleles and by observed gene diversities (defined as the frequency of pairs of gene copies, sampled in different individuals, that are different in allelic state), calculated using Genepop. IBD was analyzed by regression of â against In(distance) as above, in each compartment as well as between pairs of fruitbodies from different compartments to evaluate the differentiation between compartments. For all analyses, we have used updated version of Genepop up to version 4.5.4.

\section{Results}

\section{Maternal genetic diversity at the brûlé scale}

We investigated the diversity of maternal genotypes in fruitbodies on five brûlés (Table 2; see Figs. 2 and S3), and although this number of replicates does not allow statistical tests, some trends appeared. Spontaneous brûlés displayed more maternal MLGs (7 to 12 versus 2 to 8; Table 2), but since planted brûlés were smaller, all brûlés had similar MLG densities (on average $0.15 \mathrm{MLG} \mathrm{m}^{-2}$ ). Maternal MLG had similar sizes (Table S2) but had higher clonal diversity on spontaneous brûlés: dominant maternal MLGs accounted for 65 to $93 \%$ of the fruitbody production on planted brûlés, versus 18 to $34 \%$ on spontaneous brûlés (Table 2). Genetic diversities were similar (Table 2). When considering one by one each brûlé of the three investigated truffle-grounds (SG1, SG2 and PG1), mean brûlé size, mean maternal MLG number and mean clonal diversity were also higher on spontaneous brûlés (Table 3). 


\section{Paternal genetic diversity and inbreeding at the brûlé scale}

We investigated the zygotic genotypes, and deduced the paternal genotypes. Paternal MLGs tended to be more numerous on planted brûlés (Table 2), and the ratio of paternal to maternal MLGs was 1 to 1.4 on spontaneous brûlés versus 3.5 to 6.5 on planted ones. Paternal MLGs presented SSR alleles absent from maternal ones ( 5 to 14 per planted brûlé versus 1 to 2 per spontaneous one). Genetic diversity among paternal MLGs did not differ in planted and spontaneous brûlés; it was twice that of maternal MLGs on planted brûlés versus similar in spontaneous ones (Table 2). Paternal clonal diversity was similar over all brûlés, and three times higher on average $(0.78 \pm 0.22)$ than the maternal one (0.26 \pm 0.23 ; Table 2). Only two of the seven paternal MLGs found more than once had a significant $P_{\text {sex }}$, indicating that the two samples (MLG14 and MLG20 on PB2; Table S2) may correspond to clonemates. The sole paternal MLG also found as maternal MLG in another fruitbody (MLG11 on SB1; Fig. 2a) had a non-significant $P_{s e x}$, so that these two occurrences may not correspond to the same genet. From 12.5 to $40 \%$ of zygotic diploid genotypes per brûlé were homozygous for all SSR markers (Table 2). All brûlés showed significant heterozygote deficit, with higher zygotic $F_{I S}$ in spontaneous than in planted brûlés when considering all loci together (Table 2). When computing $F_{\text {IS }}$ for each locus separately in each brûlé, mean estimates over all loci were significantly higher on spontaneous brûlés (0.53) than on planted ones (Wilcoxon test with ties, $\mathrm{n}$ $1=36, \mathrm{n} 2=25, \mathrm{~W}=248, \mathrm{P}=0.003)$.

\section{Genetic diversity and parental tracking on mycorrhizae}

We checked whether mycorrhizae growing close to genotyped fruitbodies could be formed by one of the parents of these fruitbodies. For this, we sampled mycorrhizae from soil cores taken at the position of previously harvested fruitbodies on brûlés SB1 and PB1 (Table 1). Mycorrhizae were successfully found on 86 and 63\% of sampled positions in SB1 and PB1, respectively, with one to two 
MLGs per position. In all, six and two MLGs were recovered in SB1 and PB1, respectively, and they always had the same mating type as the maternal MLG of the focal fruitbody (Figs. 2 and S3b). Maternal MLGs of previously found fruitbodies were recovered on mycorrhizae from four (out of 11) positions on SB1 and all six positions on PB1; four of these MLGs had a significant $\mathrm{P}_{\text {sex }}$ (Table S2) so that the different occurrences of these genets may actually correspond to the same genet. Paternal MLGs were never observed on mycorrhizae (on SB1, the paternal MLG11 and MLG12 were found on remote mycorrhizae, but had a non-significant $P_{\text {sex }}$ so that the different occurrences may belong to different clones; Tables 2 and S2).

Two systematic fine-scale mycorrhizae samplings on SB1 provided 15 and 21 mycorrhizae from 0.5 and $1 \mathrm{~m}^{2}$, respectively. They revealed one to two MLGs per core, for a total number of three MLGs per fine-scale sampling area, all with mating type corresponding to that of surrounding maternal MLGs (Fig. 2). Two of these MLGs were maternal, but none were paternal on SB1 (Fig. 2a). In conclusion, some maternal, but no paternal MLGs were found on mycorrhizae surrounding fruitbodies.

\section{Strong isolation by distance on truffle-grounds}

We compared IBD for maternal MLGs on two spontaneous truffle-grounds and two plantations (Table 3 and Figs. 3 and S4). They all displayed similar diversity indices and evenness (Table 3), and significant, strong IBD for maternal MLGs: neighbourhood size estimated by Genepop ranged between 6.0 and 26.4 (Fig. 3; Table 3), and likelihood estimates of neighbourhood size were similar (with narrower confidence intervals; Table 3). These low estimates indicate that spatially close genets are genetically similar and that gene dispersion is limited to the close vicinity. Spontaneous truffle-grounds and plantations did not differ in this respect (Table 3). Among brûlés, the neighbourhood size estimates were overall roughly two-fold higher than over the whole truffle- 
ground (Table 3), and confidence intervals showed non-significant IBD among brûlés in three trufflegrounds (Table 3). However, this likely reflects the limited information in the data about differentiation among brûlés and the lower bounds of the intervals were consistent with the strong IBD pattern of the whole data.

\section{Aggregation of mating types}

Combining data from the brûlé and truffle-ground scales (Table 1), we observed 41 spontaneous brûlés and 31 planted brûlés, from which 23 and eight, respectively, showed two or more maternal MLGs (difference non-significant; Chi2=2.06; $d f=1 ; P=0.15$ ). From these, a subset of 11 spontaneous and five planted brûlés displayed a single mating type, so that spontaneous and planted trufflegrounds did not differ in mating-type aggregation at this scale (Chi2=0.004; $d f=1 ; P=0.96$ ). Aggregation was further tested by Mantel tests on the four investigated truffle-grounds on the culled MLG dataset (Table 3). Each of these tests may have low power, but they were combined by Fisher's method (see Materials and Methods) to provide a single more powerful test, which indicated aggregation of mating-type alleles $(\mathrm{df}=8 ; \mathrm{P}=0.0003)$.

\section{Interannual MLG persistence}

At the brûlé scale, maternal MLG persistence varied among brûlés, but in three out of five brûlés the maternal MLG producing the most fruitbodies was detected over three to four years (Table 2 and S2). Paternal MLG persistence was only detected once and reached two years (MLG14 from PB2 in two consecutive years; Table S2). At the truffle-ground scale, we monitored maternal MLGs only, and observed persistence over two consecutive years for 21 to 37\% of MLGs (Tables 3 and S3). $P_{\text {sex }}$ was significant for most persisting maternal MLGs, but for paternal MLG14 only, so that only the two successive occurrence of this MLG may be considered as belonging to the same clone (Table 2). 
Planted and spontaneous truffle-grounds did not differ in this respect. Combining data from both samplings, MLGs with a significant $P_{s e x}$ that persisted over at least two years produced significantly more fruitbodies per season and had a larger size (Spearman's rank correlation test, rho $=0.62$ and 0.72, respectively; $\mathrm{P}<0.001$ ). Thus, persistence was observed for maternal MLG mainly, and more frequently for the most productive genets.

\section{Diversity at the regional scale in spontaneous versus planted compartments}

Finally, we compared the genetic diversity of maternal MLGs in spontaneous versus planted compartments. We used 254 fruitbodies of two origins, namely (1) a dedicated sampling at the regional scale and (2) one representative fruitbody from the other samplings at the brûlé and truffleground scales (Tables 1 and 3). In total, we analyzed 109 fruitbodies from planted truffle-grounds and 145 from spontaneous truffle-grounds, displaying respectively 40 versus 34 private alleles and overall genetic diversity among individuals between 0.535 and 0.503 , so that genetic diversity was similar in the two compartments. The number of alleles per locus did not differ significantly between the two compartments (Wilcoxon test, $\mathrm{P}=0.46$ ) and showed no sign of genetic differentiation $\left(F_{S T}=0.03\right.$; see Principal component analysis in Fig. S5). Because compartment-related variation in genetic differentiation cannot be interpreted independently of distance, we analyzed differentiation as a function jointly of distance and of compartment type (Rousset, 1999). At the regional scale, only the planted compartment showed a significant but weak IBD (Fig. 4), so we did not find reliable evidence for homogenization by commercial exchange of $T$. melanosporum diversity among plantations. The same analysis provided no evidence for isolation between the two compartments

(Fig. 4). Indeed, a barrier to gene flow would create an excess of pairwise differentiation between populations of each compartment relative to differentiation within compartment. This excess of pairwise differentiation decreases with geographical distance, this decrease being faster when the barrier to gene flow is lower. At the lowest distance where intra- and inter- compartment pairwise 
comparisons were possible (between 68 and 160 meters, Fig.4), no excess inter-compartment mean genetic distance was observed (respectively $0.55,0.55$ and 0.50 for spontaneous, planted and between- compartment comparisons), and thus, we did not observe any sign of a barrier to gene flow between compartments.

\section{Discussion}

The analysis of 829 fruitbodies and 121 mycorrhizae provided insights into the three questions regarding T. melanosporum biology ([1]-[3], see Fig. 1, and Fig. S6 for a summary of these insights). [1] Maternal genets displayed strong IBD and significant mating-type aggregation. [2] Zygotes were highly inbred, indicating limited spatial dispersal of paternal gametes; while maternal genets (i) colonized mycorrhizae surrounding fruitbodies, and (ii) could last up to three years, paternal genets did not. [3] Genetic features differed between spontaneous truffle-grounds and plantations at the brûlé scale (lower male to female MLG ratio and higher zygotic inbreeding in spontaneous brûlés), but spontaneous and planted compartments showed no evidence for genetic isolation or for IBD at the regional scale. We discuss below how these results (Fig. S6) enlarge our knowledge of genetic resources of mycorrhizal fungi, our knowledge of the sexual reproduction and fruitbody formation in mushrooms, and the way fungal proto-domestication steps affect diversity in such species.

\section{High isolation by distance and mating type exclusion in truffle-grounds}

The extremely strong IBD for maternal genets found at the truffle-ground scale generalizes earlier reports of IBD (Bertault et al. 2001; Murat et al. 2013), and shows similar neighbourhood sizes. We also noted this at a smaller scale, since close MLGs found on mycorrhizae from the same soil cores (Figs. $2 \mathrm{~b}$ and S3b) differed at a single locus only. The neighbourhood size, previously defined in terms of axial mean-square dispersal distance $\sigma 2$ and of population density $D$ as $4 \pi D \sigma 2$ (individuals), is 
$4 \pi \sigma 2$ when the distance unit is defined such that there is on average one successful diploid genotype per surface unit (Rousset, 1997), i. e. such that $D=1$ individual. (distance unit) ${ }^{-2}$. Here $D$ should be interpreted (as a first approximation) as a successful maternal haploid genotype plus a paternal one. Then, a neighbourhood of 12 , as roughly observed, corresponds to an axial $\sigma^{2}$ of one, that is, dispersal in each dimension by the distance separating two successful genotypes. Thus, dispersal occurs mostly at the scale of the closest successful maternal genets.

While IBD is often lacking in mycorrhizal fungi forming aerial fruitbodies and wind-dispersed spores (Douhan et al. 2011; Vincenot et al. 2012), it is often high at the metric scale for species forming hypogeous, animal-dispersed spores such as the Basidiomycota Rhizopogon spp. (Kretzer et al. 2005; Dunham et al. 2013). Three non-exclusive features may contribute to the observed IBD: animal dispersal, spore persistence in soil, and possibly exclusion of unrelated individuals by genetic kin recognition.

First, dispersal by faeces entails a massive joint deposition of genetically related spores from the same fruitbody(ies) ingested by the disperser, so that in spontaneous populations local inoculum is much less mixed than for wind-dispersed species. Such a kin aggregation is reported for seed dispersal by frugivorous animals (e.g. Choo et al. 2012) or spore dispersal by insects (e.g. Giraud 2004), although its extent largely depends on feeding behaviour and digestive physiology, which account for the number of seed sources admixed in one faecal deposit. Few data are available for faecal dispersal in Tuber spp., except that ascospores survive and even increase germination after ingestion (Schickmann et al. 2012; Piattoni et al. 2014). Similarly, although methods for nursery inoculation are diverse, most inocula mix few fruitbodies, and thus harbour genetically related spores.

Second, a large spore bank of undispersed spores (undetected fruitbodies with kin spores due to inbreeding; see below) may outnumber and outcompete newly arriving spores that are genetically different, as for other hypogeous fungi (Kretzer et al. 2005; Dunham et al. 2013). Indeed, many 
fruitbodies remain undetected by well-trained dogs (Richard, Sauve, Taschen \& Selosse, pers. obs.), and undispersed spores of hypogeous fungi usually dominate the soil spore bank (Glassman et al. 2015; Taylor \& Bruns 1999), protected by their thick walls adapted to resist animal digestion (Piattoni et al. 2014). Even if direct evidence is lacking for T. melanosporum, Rhizopogon spores survive over years (Miller et al. 1994) with some dormancy (Bruns et al. 2009). Yet, IBD is less pronounced (or even absent) in Rhizopogon spp. at the metric scale as compared with $T$. melanosporum: we thus suggest that a third mechanism contributing to mating-type aggregation (see below) also enhances IBD in this species.

\section{Evidence for vegetative incompatibility from mating type exclusion}

Spatially close genets often carry identical mating types (Rubini et al. 2011a; Murat et al. 2013), and we provide the first statistical support based on culled MLG data that avoid biases due to genets producing numerous fruitbodies. Investigated mycorrhizae also displayed mating-type aggregation at the metric scale. Such aggregation seems paradoxical since the spore bank and animal dispersal co-inoculate both mating types, but experimental inoculations show that, after vegetative establishment of individuals carrying the two mating types, individuals of one MAT are progressively eliminated (Rubini et al. 2011a). The reasons remain unclear, but it is speculated that among genes controlling vegetative incompatibility, one is physically linked to the mating-type locus, or the mating-type gene itself is bifunctional, with a role in vegetative incompatibility (Murat et al. 2013; Selosse et al. 2013). In fungi, vegetative incompatibility avoids hyphal fusion between non-kin individuals carrying different alleles at controlling loci, while hyphal fusion and cooperation occur between kin carrying identical alleles (Glass et al. 2000; Richard et al. 2012). This protects against exploitation by non-kin, and secures resource acquisition for interconnected kin (Richard et al. 2012). 
Vegetative incompatibility remains undescribed for T. melanosporum (lotti et al. 2012), but exists in the related T. borchii (Sbrana et al. 2007). Moreover, the mating-type locus encodes vegetative incompatibility in some Ascomycota (Bistis 1994; Saupe 2000; Glass et al. 2000): in these species, the coexistence of nuclei with opposite mating-type alleles is not stable at the vegetative stage, but is required after the mating step within the reproductive fruitbody (Saupe 2000). Yet, for vegetative incompatibility to allow non-kin exclusion, controlling loci should be sufficiently polymorphic to indicate kinship reliably when identical (Debets \& Griffiths 1998), so that the two mating-type alleles cannot act alone. Indeed, in species where the mating type locus acts in vegetative incompatibility, additional recognition loci allow stringent assessment of kinship. If such loci exist, they would reinforce IBD by screening for relatedness among co-existing genets. Vegetative incompatibility would explain why the diverse nursery inoculation methods and the spontaneous dispersal produce similar IBD patterns and brûlé genetic diversity. Thus, in addition to inoculum dispersal, the spore bank and mechanisms driving mating-type aggregation may reinforce IBD.

\section{Evidence for restricted male gametic gene flow from biparental inbreeding.}

Zygote genotypes showed that T. melanosporum haploids are not autogamous (Riccioni et al. 2008), but displayed high inbreeding and, accordingly, significant multilocus linkage disequilibrium values (in all truffle-grounds but PG1; Table S4). Failed amplification of some alleles is unlikely to bias inbreeding estimation, because we limited the analysis to zygotes successfully amplified for both mating types, and genotyping proved reproducible (not shown). We generalize here previous reports of heterozygote deficit by Riccioni et al. (2008; reporting one or two heterozygous SSR loci [out of 5] for only 7 out of $58 T$. melanosporum fruitbodies), whose data correspond to an $F_{\text {IS }}$ of 0.41 , which is close to our values (Table 2). The related $T$. magnatum also showed high inbreeding $\left(\mathrm{F}_{\mathrm{IS}}=0.47\right.$;

Paolocci et al. 2006). The high genetic similarity between parents can be explained in the framework of the IBD described above if parents grow close together and if there is no male gamete dispersal. 
Thus, we exclude long-range dispersal of spermatia that would not entail the observed inbreeding (although we cannot exclude spermatia with an extremely small dispersal range; Fig. S1).

However, the idea that males are spatially close to maternal partners seems inconsistent with the MAT aggregation described above, which locally excludes individuals with the complementary MAT allele. Indeed, we and others (Rubini et al. 2011a; Murat et al. 2013) never detected paternal genets around the corresponding fruitbodies when investigating mycorrhizae. Although this may be explained by limited samplings, more broadly we never detected (with one exception; Fig. 2) genets with MAT different from that of the flesh of nearby fruitbodies. So where are the male genets? Once again, their origin from distant populations is excluded by the inbreeding level. Since this and other studies (Rubini et al. 2011a; Murat et al. 2013; Linde \& Selmes 2012) show that fruitbodies are not restricted to the boundaries between areas displaying different mating types (Le Tacon et al. 2015), male and paternal genets should co-occur within an area where a given mating type dominates vegetatively.

\section{Niche partition between mother and fathers}

We propose two non-exclusive hypotheses for the apparent vegetative absence of paternal genets: a smaller size and a different ecology. First, their small size (supported by high clonal diversity) and/or transience may complicate detection of their mycorrhizae. For maternal individuals, apparent persistence, size and frequency of detection among fruitbodies correlated (as in Murat et al. 2013), so that small, non-lasting paternal genets may be hardly detectable. In species where paternal genets are as large as maternal ones, each paternal genet contributes to multiple fertilizations, as described in some Ascomycota (Guidot et al. 2003) and plant species (Lian et al. 2001), whereas here, T. melanosporum paternal genets contributed to fewer zygotes than maternal genets (see clonal diversity in Table 2). Second, a different ecology of paternal mycelia may limit the relevance of 
our root samplings: paternal genets may not form mycorrhizae. They may survive briefly as saprotrophs, thanks to the diverse enzymatic gene set in T. melanosporum (Martin et al. 2010). They may also colonize and parasitize roots of herbaceous plants, as suggested by Plattner \& Hall (1995) and Gryndler et al. (2014), an interaction that may explain the poor vegetation growth on the brûlés. The existence of small-sized, free-living mycelia would explain why, even without specific methods for spore DNA extraction, one can detect in soil alleles that are absent from the vegetative mycorrhizal population (Belfiori et al. 2012; Rubini et al. 2011a). In an extreme scenario, germinating ascospores may act as gametes, since spores from both mating types co-occur in undetected fruitbodies or deposited inoculum. At present, we lack direct evidence for the intriguing possibility that germlings are recruited as paternal genets, and one surviving paternal genet (MLG14 on PB2) suggested that there could be more than short-term germination. Altogether, we hypothesize dwarf paternal mycelia or even germlings (Selosse et al. 2013), avoiding the mating-type exclusion on mycorrhizae by way of a different ecology.

Thus, in our interpretation, spores can contribute to mating in two exclusive ways at a given site: some, having the mating type that became locally dominant after population settlement, can establish mycorrhizae and act as mothers that invest resources collected on trees to support ascospores maturation; the others, having the complementary mating type, do not (or poorly) colonize the same niche, but achieve mating, perhaps the only reproductive effort they can afford given their limited access to mycorrhizal resources. The type of reproductive effort would then fit the available resources, fitting a size-advantage model well known from animal and plant models (Warner, 1988). Species where meiotic spores from the same zygote are dispersed together and where mating thereafter occurs among spatially close haploids undergo high inbreeding, as described in Microbotryum violaceum (Giraud et al. 2005) and Cyathus stercoreus (Malloure \& James 2013). Yet, given its predominantly haploid life cycle where diploidy is transient (Fig. S1), T. melanosporum is insensitive to inbreeding depression. Although T.melanosporum mycelium is potentially hermaphroditic (i.e. capable of paternal or maternal contribution; Korf 1973; Le Tacon et 
al. 2015), it undergoes forced functional dioecism due to the local mating-type aggregation. Future studies may reveal the nature of paternal mycelia, as well as the mechanisms by which fertilization is achieved.

\section{Spontaneous and planted populations differ at the local scale}

Increasing, often empirical, efforts are being made to control the production of forest mushrooms, and T. melanosporum illustrates proto-domestication attempts made since the $19^{\text {th }}$ century (Chatin 1869). We investigate how such attempts affect genetic resources and other above features, by comparing plantations and spontaneous truffle-grounds. We found a lower number of maternal genets (but producing more fruitbodies), a higher number of paternal genets and less inbreeding in plantations at the brûlé level. Future efforts may further support the trends and mechanisms discussed below.

Brûlés tended to be larger in spontaneous truffle-grounds, due to coalescence between some brûlés, whereas regularly spaced trees in plantations maintain independent brûlés, but the density of maternal genets was similar everywhere. Strikingly, paternal genets again showed different trends compared with maternal ones. They were more numerous on planted than on spontaneous brûlés (especially when normalizing by brûlé area), and their genetic diversity was higher than that of females in plantation brûlés, but not on spontaneous brûlés. Zygotes also displayed a lower heterozygote deficiency in plantations and, congruently with a higher recombination in plantations, multilocus linkage disequilibrium values were non-significant in PG1 and concerned fewer pairs of loci only in PG2 (Table S4), while heterozygote deficiency was significant in spontaneous trufflegrounds. 
The reasons why maternal genets are more productive in planted brûlés remain unclear, but may relate to differences in access to mycorrhizae and tree resources after nursery inoculation. Inoculation practices in planted brûlés may explain the trends observed for paternal and zygotic diversity: beyond initial tree inoculation, recurrent scattering of fruitbody fragments is performed on plantation soil, which adds up to the discontinuous and sparser spore flow by faecal depositions (Murat 2014). The paternal population could incorporate these diverse incomers, especially if, as stated above, spore germlings act as males and if paternal individuals bypass kin exclusion by vegetative incompatibility, thanks to a niche differing from mother individuals. Conversely, vegetative incompatibility would always level maternal diversity. A higher diversity of male genets in plantations explains, in turn, the lower heterozygote deficit. This differs strikingly from many domesticated plant populations where heterozygote deficit is often higher (Glémin \& Bataillon 2009; Parker et al. 2014) than in wild counterparts. In the future, experimental deposition of genetically characterized ascospores could test their contribution to zygotic genotypes.

\section{Spontaneous and planted populations are not isolated at the regional scale}

Our results revealed no differentiation at larger scales between spontaneous and planted compartments in Southern France, invalidating our predictions of lower diversity and spatial heterogeneity in the proto-domesticated compartment.

At the regional scale, the planted compartment showed a weak IBD, implying that commercial exchanges did not successfully homogenize diversity in plantations. Many truffle growers use their own, local inoculum, and trees inoculated by large commercial nurseries, which are the most prone to homogenize regional populations, do not yet show significant effects. We are not aware of any tracing of exchange of inoculated trees, but if IBD is confirmed over other regions, conservation of local genetic diversity will require limitation of exchanges of inoculant and inoculated trees in the 
future. The absence of IBD in the spontaneous compartment is unexpected in this context: since confidence intervals overlap for the two compartments (Fig. 4), a similar weak IBD may also exist in natura, as reported at a higher scale by Murat et al. (2004) and Riccioni et al. (2008), although not statistically detected in our data. The weak IBD at the regional scale may be due either to high dispersal, or to some limits of our markers. Animal dispersal allows long-distance gene flow (Frank et al. 2009): large herbivores ingesting truffles, such as deer and wild boar, can travel more than $2 \mathrm{~km}$ over 48 hours (Janeau \& Spitz 1984; Pellerin et al. 2016) and occupy areas up to $150 \mathrm{~km}^{2}$ (Janeau \& Spitz, 1984), which explains why hypogeous fungi colonize pioneer trees as efficiently as winddispersed fungi (Ashkannejhad \& Horton 2006). Yet the weak regional IBD observed may also result from high mutation rates at SSR loci (Rousset, 1997) or from non-equilibrium patterns of population expansion (Slatkin 1993). In particular, weak IBD in T. melanosporum may be the legacy of a fast post-glacial range re-colonization (Murat et al. 2004).

Planted and spontaneous compartments were not genetically isolated and exhibited similar genetic diversity, strongly differing from the bottleneck often observed in the domestication process (Glémin \& Bataillon 2009; Gross \& Olsen 2010; Qi et al. 2013). This is probably because (i) plantations and spontaneous truffle-grounds are sympatric, (ii) growers' inoculant sources and wild animals efficiently mix populations from plantations and surrounding areas. That $T$. melanosporum did not undergo major genetic changes and isolation due to human action confirms that we are at an early domestication step, although the analysis of neutral loci does not exclude that selection acts on a few important loci. The inter-annual survival of maternal genets suggests that the domestication of perennial plants rather than that of annual crop species is a relevant comparison for T. melanosporum. Such perennials naturally show less population structure than annual plants (Duminil \& Michele 2009; Miller \& Gross 2011), and during domestication often undergo a smaller bottleneck and inbreeding increase than annual crops (Miller \& Gross 2011), especially in their area of origin, where domesticated and wild populations maintain genetic exchanges (Delplancke et al. 
Absence of isolation between compartments and increase in paternal diversity, due to incomplete domestication and possibly to management, now need to be confirmed in other regions, and at a larger scale. T. melanosporum turns out to be a relevant model of early fungal domestication. Interestingly, truffle-grounds in the Southern Hemisphere (Linde \& Selmes 2012), where T. melanosporum has been introduced far from spontaneous populations, now await comparative approaches.

\section{Conclusions}

The population genetics of $T$. melanosporum cumulates specific traits related to the Ascomycota haploid life cycle (Fig. 1; see summary in Fig. S6) and to animal dispersal. Our study first provides extended support, especially in spontaneous truffle grounds, for three previously suggested patterns: it demonstrates that strong IBD at the truffle-ground scale is a general phenomenon, including in spontaneous truffle-grounds; it provides statistical support for mating-type aggregation; and it confirms inter-annual persistence and presence on mycorrhizae of maternal genets. Second, a new finding arises from zygote analyses that reveal high inbreeding. Relatedness between parents implies the immediate vicinity of paternal gametes and excludes long-distance male gamete dispersal. Third, we show that unlike the large, sometimes lasting maternal genets detected on mycorrhizae, paternal genets contribute to fewer zygotes, are less lasting and are undetected on mycorrhizae. A different niche for paternal mycelia is thus likely, by-passing mating-type aggregation. An intriguing possibility is that germlings from the spore bank (made of undispersed and/or jointly dispersed kin spores) act as a paternal source. Although hermaphroditic, $T$. melanosporum displays site-dependant functional dioecism, driven by the locally dominant mating type. Finally, we found a limited impact of plantation practices, except on male diversity.

Considering T. melanosporum proto-domestication, we call for more replicate studies, at a larger 
scale and out of its area of origin to understand the impact of proto-domestication on fungal genetic resources.

Acknowledgements - We thank the truffle-ground owners Pierre Bernadach (SB1), Christophe Bot (SB2), Jean-Paul Laurents (PB1 and 2), Gilbert Serane (PB3, PG2), Paul Stengel (SG1), Jean-François Tourrette (SG2), and Annie Guillen, Hervé Coves, Alain Champagnac, Sylvain Foissac and Frederique Serre for access to field sites and help in sampling, as well as the 63 truffle growers who contributed to the regional sampling. This work was funded by the French Agence Nationale de la Recherche (programme SYSTERRA) and the Région Languedoc-Roussillon (program SYSTERRA-LR), with the support of the Centre d'Etudes Techniques et de Formation Forestières Languedoc-Roussillon, and the Fédération Française des Trufficulteurs. We also thank Bernard Assenat and Daniel Mousain for their help in sampling, Fabien Halkett and Adrien Taudière for discussions on statistical analyses, Michel Raymond, Diana Fernandez and Gabriel Callot for access to samples (PB3), Marie-Hélène Muller and Sylvain Glémin for discussions on domestication, Martina Peter for precious comments on the manuscript, Laure Schneider-Maunoury for help with Fig. S1, as well as Claude Murat for access to PG2 data. Four anonymous referees and Tatiana Giraud helped to improve this paper, and D. Marsh corrected the English. Molecular genetic analyses were performed thanks to the technical facilities of the Laboratoire d'Excellence "Centre Méditerranéen de l'Environnement et de la Biodiversité". M.-A. Selosse is supported by the Laboratoire d'Excellence BCDiv. E. Taschen is funded by the Fondation de France.

\section{References}

Arnaud-Haond S, Belkhir K (2007) genclone: a computer program to analyse genotypic data, test for clonality and describe spatial clonal organization. Molecular Ecology Notes, 7, 15-17.

Ashkannejhad S, Horton TR (2006) Ectomycorrhizal ecology under primary succession on coastal sand dunes: interactions involving Pinus contorta, suilloid fungi and deer. New Phytologist, 169, 345354.

Belfiori B, Riccioni C, Tempesta S, Pasqualetti M, Paolocci F, Rubini A (2012) Comparison of ectomycorrhizal communities in natural and cultivated Tuber melanosporum truffle grounds. FEMS Microbiology Ecology, 81, 547-561.

Bertault G, Rousset F, Fernandez D, Berthomieu A, Hochberg M E, Callot G, Raymond M. (2001) Population genetics and dynamics of the black truffle in a man-made truffle field. Heredity, 86, 451458.

Billiard S, Lopez-Villavicencio M, Hood ME, Giraud T (2012) Sex, outcrossing and mating types: unsolved questions in fungi and beyond. Journal of evolutionary biology, 25, 1020-1038. 
Bistis GN (1994) Retardation of the growth of transplanted apothecia: a manifestation of vegetative incompatibility in Ascobolus stercorarius (Bull.) Schröt. Experimental Mycology, 18, 103-110.

Bruns TD, Peay KG, Boynton PJ, Grubisha LC, Hynson NA, Nguyen NH, Rosenstock NP. (2009) Inoculum potential of Rhizopogon spores increases with time over the first $4 \mathrm{yr}$ of a 99-yr spore burial experiment. New Phytologist, 181, 463-470.

Bultman TL, White JF Jr, Bowdish TI, Welch AM (1998) A new kind of mutualism between fungi and insects. Mycological Research, 102, 235-238.

Callot G (1999) La truffe, la terre, la vie. Editions INRA, Paris.

Chang ST, Hayes WA (2013) The biology and cultivation of edible mushrooms. Academic Press, Amsterdam, Boston.

Chatin AD (1869) La Truffe. Etude des conditions générales de la production truffière, 1st edition. Bouchard-Huzard, Paris.

Cheeseman K, Ropars J, Renault, P, Dupont J, Gouzy J, Branca A, Ceppi M, Debuchy R, Malagnac F, Goarin A, Silar P, Lacoste S, Sallet E, Bensimon A, Giraud T, Brygoo Y (2014) Multiple recent horizontal transfer of a large genomic region between cheese fungi. Nature Communications, B, 2876.

Choo J, Juenger TE, Simpson BB (2012) Consequences of frugivore-mediated seed dispersal for the spatial and genetic structures of a neotropical palm. Molecular Ecology, 21, 1019-1031.

Debets AJM, Griffiths AJF (1998) Polymorphism of het-genes prevents resource plundering in Neurospora crassa. Mycological Research, 102, 1343-1349.

Debuchy R, Berteaux-Lecellier V, Silar P (2010) Mating systems and sexual morphogenesis in ascomycetes. In: Cellular and Molecular Biology of Filamentous Fungi, Editors: Borkovitch K, Ebbole D. ASM Press, Washington DC, pp. 501-535.

Delplancke M, Alvarez N, Espíndola A, Joly H, Benoit L, Brouck E, Arrigo N (2012) Gene flow among wild and domesticated almond species: insights from chloroplast and nuclear markers. Evolutionary Applications, 5, 317-329.

Dorken ME, Eckert CG (2001) Severely reduced sexual reproduction in northern populations of a clonal plant, Decodon verticillatus (Lythraceae). Journal of Ecology, 89, 339-350.

Douet JP, Castroviejo M, Mabru D,Chevalier G, Dupré C, Bergougnoux F, Ricard JM, Médina B(2004) Rapid molecular typing of Tuber melanosporum, $T$. brumale and $T$. indicum from tree seedlings and canned truffles. Analytical and Bioanalytical Chemistry, 379, 668-673.

Douhan GW, Huryn KL, Douhan LI (2007) Significant diversity and potential problems associated with inferring population structure within the Cenococcum geophilum species complex. Mycologia, 99, 812-819. 
Douhan GW, Vincenot L, Gryta H, Selosse M-A (2011) Population genetics of ectomycorrhizal fungi: from current knowledge to emerging directions. Fungal Biology, 115, 569-597.

Duminil J, Michele MD (2009) Plant species delimitation: A comparison of morphological and molecular markers. Plant Biosystems, 143, 528-542.

Dunham SM, Mujic AB, Spatafora JW, Kretzer AM (2013) Within-population genetic structure differs between two sympatric sister-species of ectomycorrhizal fungi, Rhizopogon vinicolor and $R$. vesiculosus. Mycologia, 105, 814-826.

El Karkouri K, Selosse MA, Mousain D (2006) Molecular markers detecting an ectomycorrhizal Suillus collinitus strain on Pinus halepensis roots suggest successful inoculation and persistence in Mediterranean nursery and plantation. FEMS Microbiology Ecology, 55, 146-158.

Fager EW (1972) Diversity: A sampling study. The American Naturalist, 106, 293-310.

Fisher RA (1925) Statistical Methods for Research Workers. Oliver and Boyd, Edinburgh.

Frank JL, Anglin S, Carrington EM, Taylor DS, Viratos B, Southworth D (2009) Rodent dispersal of fungal spores promotes seedling establishment away from mycorrhizal networks on Quercus garryana. Botany, 87, 821-829.

Giraud T (2004) Patterns of within population dispersal and mating of the fungus Microbotryum violaceum parasitising the plant Silene latifolia. Heredity, 93, 559-565.

Giraud T, Jonot O, Shykoff JA (2005) Selfing propensity under choice conditions in a parasitic fungus, Microbotryum violaceum, and parameters influencing infection success in artificial inoculations. International Journal of Plant Sciences, 166, 649-657.

Glass NL, Jacobson DJ, Shiu PKT (2000) The genetics of hyphal fusion and vegetative incompatibility in filamentous Ascomycete fungi. Annual Review of Genetics, 34, 165-186.

Glassman SI, Peay KG, Talbot JM, Smith DP, Chung JA, Taylor JW, Vilgalys R, Bruns TD. (2015) A continental view of pine-associated ectomycorrhizal fungal spore banks: a quiescent functional guild with a strong biogeographic pattern. New Phytologist, 205, 1619-1631.

Glémin S, Bataillon T (2009) A comparative view of the evolution of grasses under domestication. New Phytologist, 183, 273-290.

Gross BL, Olsen KM (2010) Genetic perspectives on crop domestication. Trends in Plant Science, 15, 529-537.

Guidot A, Johannesson H, Dahlberg A, Stenlid J (2003) Parental tracking in the postfire wood decay ascomycete Daldinia loculata using highly variable nuclear gene loci. Molecular Ecology, 12, 17171730.

Hall IR, Brown GT, Zambonelli A (2008). Taming the Truffle: The History, Lore, and Science of the Ultimate Mushroom. Timber Press, Portland 
Healy RA, Smith ME, Bonito GM, Pfister DH, Ge ZW, Guevara GG, Williams G, Stafford K, Kumar L, Lee T, Hobart C, Trappe J, Vilgalys R, McLaughin DJ (2013) High diversity and widespread occurrence of mitotic spore mats in ectomycorrhizal Pezizales. Molecular Ecology, 22, 1717-1732.

van der Heijden MGA, Martin FM, Selosse MA, Sanders IR (2015) Mycorrhizal ecology and evolution: the past, the present, and the future. New Phytologist, 205, 1406-1423.

Hochberg ME, Bertault G, Poitrineau K, Janssen A (2003) Olfactory orientation of the truffle beetle, Leiodes cinnamomea. Entomologia Experimentalis et Applicata, 109, 147-153.

lotti M, Rubini A, Tisserant $E$, Kholer A, Paolocci F, Zambonelli A (2012) Self/nonself recognition in Tuber melanosporum is not mediated by a heterokaryon incompatibility system. Fungal Biology, 116, 261-275.

Janeau G, Spitz F (1984) L'espace chez le sanglier (Sus scrofa scrofa L.) : occupation et mode d'utilisation. Gibier faune sauvage, 1, 73-89.

Korf RP (1973) Discomycetes and Tuberales. In: The Fungi: An Advanced Treatise. Editors: Ainsworth GC, Sparrow FK, Sussman AS. New York, pp. 249-319.

Kretzer AM, Dunham S, Molina R, Spatafora JW (2005) Patterns of vegetative growth and gene flow in Rhizopogon vinicolor and R. vesiculosus (Boletales, Basidiomycota). Molecular Ecology, 14, 22592268.

Le Tacon F, Rubini A, Murat C, Riccioni C, Robin C, Belfiori B, Zeller B, De la Varga H, Akroume E, Deveau A, Martin F, Paolocci $F$ (2015) Certainties and uncertainties about the life cycle of the Périgord black truffle (Tuber melanosporum Vittad.). Annals of Forest Science, 73, 105-117.

Le Tacon F, Zeller B, Plain C, Hossann C, Brechet C, Robin C (2013) Carbon transfer from the host to Tuber melanosporum mycorrhizas and ascocarps followed using a ${ }^{13} \underline{C}$ pulse-labeling technique. $P$ LoS ONE, 8, e64626.

Levene H (1949) On a matching problem arising in genetics. The Annals of Mathematical Statistics, 20,91-94.

Lian C, Miwa M, Hogetsu T (2001) Outcrossing and paternity analysis of Pinus densiflora (Japanese red pine) by microsatellite polymorphism. Heredity, 87, 88-98.

Linde CC, Selmes H (2012) Genetic diversity and mating type distribution of Tuber melanosporum and their significance to truffle cultivation in artificially planted truffières in Australia. Applied and Environmental Microbiology, 78, 6534-6539.

Malloure BD, James TY (2013) Inbreeding depression in urban environments of the bird's nest fungus Cyathus stercoreus (Nidulariaceae: Basidiomycota). Heredity, 110, 355-362.

Martin F, Kohler A, Murat C et al. (2010) Périgord black truffle genome uncovers evolutionary origins and mechanisms of symbiosis. Nature, 464, 1033-1038. 
Mello A, Lumini E, Napoli C, Bianciotto V, Bonfante P (2015) Arbuscular mycorrhizal fungal diversity in the Tuber melanosporum brûlé. Fungal Biology, 119, 518-527.

Miguel AM, Águeda B, Sánchez S, Parladé J (2014) Ectomycorrhizal fungus diversity and community structure with natural and cultivated truffle hosts: applying lessons learned to future truffle culture. Mycorrhiza, 24, 5-18.

Miguel AM, Saez R (2005) Algunas micorrizas competidoras de plantaciones truferas. Publicaciones de Biología de la Universidad de Navarra, Serie Botánica, 16, 1-18.

Miller AJ, Gross BL (2011) From forest to field: Perennial fruit crop domestication. American Journal of Botany, 98, 1389-1414.

Miller SL, Torres P, McClean TM (1994) Persistence of basidiospores and sclerotia of ectomycorrhizal fungi and Morchella in soil. Mycologia, 86, 89-95.

Murat C (2014) Forty years of inoculating seedlings with truffle fungi: past and future perspectives. Mycorrhiza, 25, 77-81.

Murat C, Díez J, Luis P, Delaruelle C, Dupré C, Chevalier G, Bonfante P, Martin F (2004) Polymorphism at the ribosomal DNA ITS and its relation to postglacial re-colonization routes of the Perigord truffle Tuber melanosporum. New Phytologist, 164, 401-411.

Murat C, Riccioni C, Belfiori B, Cichocki N, Labbé J, Morin E, Tisserant E, Paolocci F, Rubini A, Martina F. (2011) Distribution and localization of microsatellites in the Perigord black truffle genome and identification of new molecular markers. Fungal Genetics and Biology, 48, 592-601.

Murat C, Rubini A, Riccioni C, Akroume E, Belfiori B, Guaragno M, Le Tacon F, Robin C, Halkett F, Martin F, Paolocci F (2013) Fine-scale spatial genetic structure of the black truffle (Tuber melanosporum) investigated with neutral microsatellites and functional mating type genes. New Phytologist, 199, 176-187.

Murphy DJ (2007) People, plants and genes. The Story of Crops and Humanity. Oxford University Press, Oxford.

Paolocci F, Rubini A, Riccioni C, Arcioni S (2006) Reevaluation of the life cycle of Tuber magnatum. Applied and Environmental Microbiology, 72, 2390-2393.

Parker KC, Trapnell DW, Hamrick JL, Hodgson WC (2014) Genetic and morphological contrasts between wild and anthropogenic populations of Agave parryi var. huachucensis in south-eastern Arizona. Annals of Botany, 113, 939-952.

Parks JC, Werth CR (1993) A study of spatial features of clones in a population of bracken fern, Pteridium aquilinum (Dennstaedtiaceae). American Journal of Botany, 80, 537-544. 
Pellerin M, Picard M, Sonia S, Baubet E, Baltzinger C (2016) Complementary endozoochorous longdistance seed dispersal by three native herbivorous ungulates in Europe. Basic and Applied Ecology, in press.

Piattoni F, Amicucci A, lotti M, Ori F, Stocchi V, Zambonelli A (2014) Viability and morphology of Tuber aestivum spores after passage through the gut of Sus scrofa. Fungal Ecology, 9, 52-60.

Qi J, Liu X, Shen D, Miao H, Xie B, Li X, Zeng P, Wang S, Shang Yi, Gu X, Du Y, et al. (2013) A genomic variation map provides insights into the genetic basis of cucumber domestication and diversity. Nature Genetics, 45, 1510-1515.

Raymond M, Rousset F (1995) An exact test for population differentiation. Evolution, 49, 1280-1283.

R Core Team (2014) R: A language and environment for statistical computing. R Foundation for Statistical Computing, Vienna, Austria. ISBN 3-900051-07-0, URL http://www.R-project.org.

Riccioni C, Belfiori B, Rubini, Passeri V, Arcioni S, Paolocci F (2008) Tuber melanosporum outcrosses: analysis of the genetic diversity within and among its natural populations under this new scenario. New Phytologist, 180, 466-478.

Richard F, Glass NL, Pringle A (2012) Cooperation among germinating spores facilitates the growth of the fungus, Neurospora crassa. Biology letters, 8, 419-422.

Robertson A, Hill WG (1984) Deviations from Hardy-Weinberg proportions: sampling variances and use in estimation of inbreeding coefficients. Genetics, 107, 703-718.

Rousset $F$ (1997) Genetic differentiation and estimation of gene flow from F-Statistics under isolation by distance. Genetics, $145,1219-1228$.

Rousset F (1999) Genetic differentiation in populations with different classes of individuals. Theoretical Population Biology, 55, 297-308.

Rousset (2000) Genetic differentiation between individuals. Journal of Evolutionary Biology, 13, 5862.

Rousset F (2008) genepop'007: a complete re-implementation of the genepop software for Windows and Linux. Molecular Ecology Resources, 8, 103-106.

Rousset F, Leblois R (2007) Likelihood and approximate likelihood analyses of genetic structure in a linear habitat: Performance and robustness to model mis-specification. Molecular Biology and Evolution, 24, 2730-2745.

Rousset F, Leblois R (2012) Likelihood-based inferences under isolation by distance: Twodimensional habitats and confidence intervals. Molecular Biology and Evolution, 29, 957-973. 
Rubini A, Belfiori B, Riccioni C, Arcioni S, Martin F, Paolocci F (2011a) Tuber melanosporum: mating type distribution in a natural plantation and dynamics of strains of different mating types on the roots of nursery-inoculated host plants. New Phytologist, 189, 723-735.

Rubini A, Belfiori B, Riccioni C, Tisserant E, Arcioni S, Martin F, Paolocci F (2011b) Isolation and characterization of MAT genes in the symbiotic ascomycete Tuber melanosporum. New Phytologist, 189, 710-722.

Rubini A, Riccioni C, Belfiori B, Paolocci F (2014) Impact of the competition between mating types on the cultivation of Tuber melanosporum: Romeo and Juliet and the matter of space and time. Mycorrhiza, 24, 19-27.

Saupe SJ (2000) Molecular genetics of heterokaryon incompatibility in filamentous ascomycetes. Microbiology and Molecular Biology Reviews, 64, 489-502

Sbrana C, Nuti MP, Giovannetti M (2007) Self-anastomosing ability and vegetative incompatibility of Tuber borchii isolates. Mycorrhiza, 17, 667-675.

Schickmann S, Urban A, Kräutler K, Nopp-Mayr U, Hackländer K (2012) The interrelationship of mycophagous small mammals and ectomycorrhizal fungi in primeval, disturbed and managed Central European mountainous forests. Oecologia, 170, 395-409.

Selosse M-A, Taschen E, Giraud T (2013) Do black truffles avoid sexual harassment by linking mating type and vegetative incompatibility? New Phytologist, 199, 10-13.

Slatkin M (1993) Isolation by distance in equilibrium and non-equilibrium populations. Evolution, 47, 264-279.

Stenberg P, Lundmark M, Saura A (2003) mlgsim: a program for detecting clones using a simulation approach. Molecular Ecology Notes, 3, 329-331.

Streiblová E, Gryndlerová H, Gryndler M (2012) Truffle brûlé: an efficient fungal life strategy. FEMS Microbiology Ecology, 80, 1-8.

Taylor DL, Bruns TD (1999) Community structure of ectomycorrhizal fungi in a Pinus muricata forest: minimal overlap between the mature forest and resistant propagule communities. Molecular Ecology, 8, 1837-1850.

Tedersoo L, Hansen K, Perry BA, Kjøller R (2006) Molecular and morphological diversity of pezizalean ectomycorrhiza. New Phytologist, 170, 581-596.

Urban A, Neuner-Plattner I, Krisai-Greilhuber I, Haselwandter K (2004) Molecular studies on terricolous microfungi reveal novel anamorphs of two Tuber species. Mycological Research, 108, 749-758.

Vincenot L, Nara K, Sthultz C, Labbe J, Dubois M-P, Tedersoo L, Martin M, Selosse M-A (2012) Extensive gene flow over Europe and possible speciation over Eurasia in the ectomycorrhizal basidiomycete Laccaria amethystina complex. Molecular Ecology, 21, 281-299. 
Warner RR (1988). Sex change and the size-advantage model. Trends in Ecology \& Evolution, 3, 133136.

Zambonelli A, Bonito GM (Eds.) (2012) Edible Ectomycorrhizal Mushrooms. Springer Berlin Heidelberg, Berlin, Heidelberg.

Zeder MA (2008) Domestication and early agriculture in the Mediterranean Basin: Origins, diffusion, and impact. Proceedings of the National Academy of Sciences, 105, 11597-11604.

Zampieri E, Rizzello R, Bonfante P, Mello A (2012) The detection of mating type genes of Tuber melanosporum in productive and non-productive soils. Applied Soil Ecology, 57, 9-15

\section{Data accessibility:}

All used data are available at DRYAD Digital Repositor doi:10.5061/dryad.vm11r (http://dx.doi.org/10.5061/dryad.vm11r).

- Sampling information (location, season) and genotyping data (SSR and mating type) at brûlé, truffle-ground and regional scales.

- Zygotic genotypes and R script to estimate heterozygote deficits.

\section{Authors' contribution box:}

This manuscript is part of E.T.'s PhD thesis. M.-A.S. designed the research with help from F.Ri. and E.T.; E.T. and M.S. sampled the truffles and performed the molecular analyses with help from L.B. and M.-P.D. Data analyses were performed by E.T. under the supervision of M.-A.S. and F. Ro., and the paper was first written by E.T. and M.-A.S., with help from F.Ro. All authors then improved the manuscript. 
Table 1. Sampling design at three scales, with number of collected samples and the three questions addressed (as in Fig. 1).

\begin{tabular}{|c|c|c|c|c|c|c|c|c|c|c|}
\hline \multirow[b]{2}{*}{$\begin{array}{l}\text { Study } \\
\text { scale }\end{array}$} & \multirow[b]{2}{*}{ Site } & \multirow[b]{2}{*}{$\begin{array}{l}\text { Geographic } \\
\text { position }\end{array}$} & \multirow[b]{2}{*}{ Type $^{1}$} & \multicolumn{3}{|c|}{ Samples } & \multicolumn{4}{|c|}{ Analyses } \\
\hline & & & & Sampling & $\begin{array}{l}\text { Fruit- } \\
\text { bodies }^{2}\end{array}$ & $\begin{array}{l}\text { Myco- } \\
\text { rrhizae }\end{array}$ & $\begin{array}{l}\text { [1] } \\
\text { Genetic } \\
\text { diversity } \\
\text { and IBD }\end{array}$ & $\begin{array}{l}\text { [1] MLG persis- } \\
\text { tence and } \\
\text { mating-type } \\
\text { aggregation }\end{array}$ & $\begin{array}{l}\text { [2] Zygotic and } \\
\text { paternal MLG, } \\
\text { inbreeding }\end{array}$ & $\begin{array}{l}\text { [3] } \\
\text { Comparison } \\
\text { planted / } \\
\text { spontaneous }\end{array}$ \\
\hline \multirow[t]{5}{*}{ Brûlé } & SB1 & $\begin{array}{l}42^{\circ} 44^{\prime} 21^{\prime \prime} \mathrm{N}, \\
2^{\circ} 28^{\prime} 57^{\prime \prime} \mathrm{E}\end{array}$ & $\mathrm{S}$ & $\begin{array}{l}2010 \text { to } \\
2014\end{array}$ & 40 & 91 & & & & \\
\hline & SB2 & $\begin{array}{l}43^{\circ} 26^{\prime} 48^{\prime \prime} \mathrm{N}, \\
3^{\circ} 22^{\prime} 46^{\prime \prime} \mathrm{E}\end{array}$ & $\mathrm{S}$ & $\begin{array}{l}2010 \text { to } \\
2014\end{array}$ & 22 & - & & & & \\
\hline & PB1 & $\begin{array}{l}44^{\circ} 01^{\prime} 18^{\prime \prime} \mathrm{N}, \\
3^{\circ} 18^{\prime} 02^{\prime \prime} \mathrm{E}\end{array}$ & $P$ & $\begin{array}{l}2010 \text { to } \\
2014\end{array}$ & 32 & 30 & & $\checkmark$ & $\checkmark$ & $\checkmark$ \\
\hline & PB2 & $\begin{array}{l}44^{\circ} 01^{\prime} 18^{\prime \prime} \mathrm{N}, \\
3^{\circ} 18^{\prime} 02^{\prime \prime} \mathrm{E}\end{array}$ & $P$ & $\begin{array}{l}2010 \text { to } \\
2014\end{array}$ & 39 & - & & & & \\
\hline & PB3 & $\begin{array}{l}43^{\circ} 44^{\prime} 39^{\prime \prime} \mathrm{N}, \\
3^{\circ} 42^{\prime} 20^{\prime \prime} \mathrm{E}\end{array}$ & $P$ & $\begin{array}{l}1995 \text { to } \\
1997^{3}\end{array}$ & 19 & - & & & & \\
\hline Truffle- & SG1 & $\begin{array}{l}44^{\circ} 01^{\prime} 50^{\prime \prime} \mathrm{N}, \\
4^{\circ} 22^{\prime} 49^{\prime \prime} \mathrm{E}\end{array}$ & $S$ & $\begin{array}{l}2013 \text { to } \\
2014\end{array}$ & 263 & - & & & & \\
\hline ground & SG2 & $\begin{array}{l}43^{\circ} 59^{\prime} 05^{\prime \prime} \mathrm{N}, \\
5^{\circ} 07^{\prime} 13^{\prime \prime} \mathrm{E}\end{array}$ & $S$ & $\begin{array}{l}2013 \text { to } \\
2014\end{array}$ & 89 & - & $\checkmark$ & $\checkmark$ & & $\checkmark$ \\
\hline & PG1 & $43^{\circ} 44^{\prime} 39^{\prime \prime} \mathrm{N}$, & $\mathrm{P}$ & 2013 to & 147 & - & & & & \\
\hline
\end{tabular}




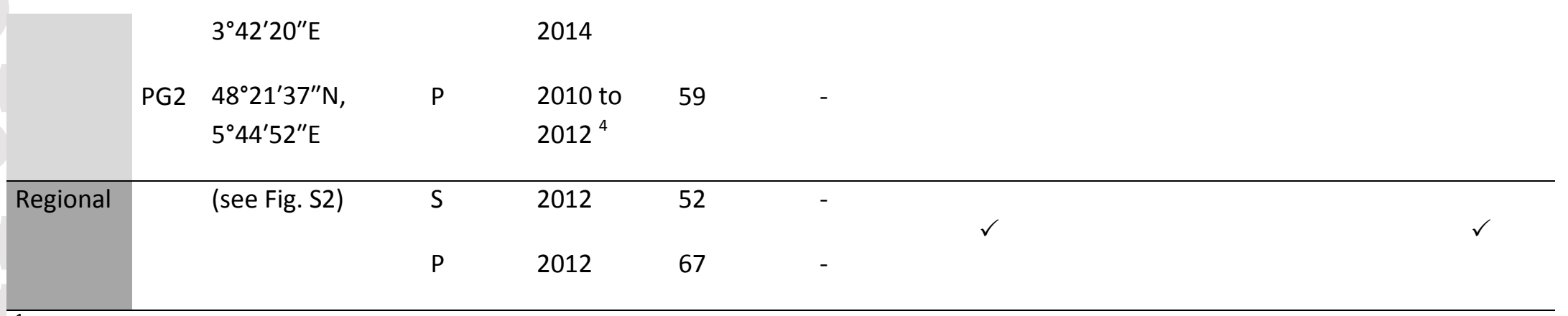

${ }^{1} \mathrm{~S}$, spontaneous truffle-ground; $\mathrm{P}$, plantation.

${ }^{2}$ Number of fruitbodies, mycorrhizae were sampled in 2011 only.

${ }^{3}$ Samples from Bertault et al. (2001), reanalyzed for this study based on a new genotyping.

${ }^{4}$ Data published by Murat et al. (2013), reanalyzed in this study for spatial analyses only.

Table 2. Genetic diversity on the two spontaneous brûlés (SB1 and SB2) and three planted brûlés (PB1, PB2 and PB3).

\begin{tabular}{|c|c|c|c|c|c|}
\hline Sites & SB1 & SB2 & PB1 & PB2 & PB3 \\
\hline 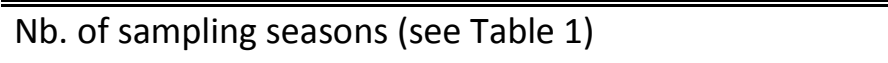 & 3 & 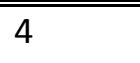 & 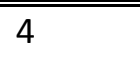 & 4 & 3 \\
\hline Mean diameter of the brûlé $(\mathrm{m})$ & 5.5 & 5.5 & 3.5 & 3.5 & 2.0 \\
\hline Nb. of sampled fruitbodies ( $n b$. maternally genotyped ${ }^{1}$ ) & $40(29)$ & $22(11)$ & $32(28)$ & $39(35)$ & $19(15)$ \\
\hline Nb. of maternal MLGs (nb. MAT1-2 and 1-2) & $12(10 ; 2)$ & $7(4 ; 3)$ & $2(0 ; 2)$ & $8(1 ; 7)$ & $2(2 ; 0)$ \\
\hline Max. fruitbody number per maternal MLG & 10 & 2 & 22 & 23 & 14 \\
\hline
\end{tabular}


Maternal clonal diversity

Genetic diversity among maternal MLGs

$\mathrm{Nb}$. of persistent maternal MLGs (over max. 2; 3; 4 years)

Nb. of genotyped zygotes ${ }^{2}$ (nb. paternally genotyped ${ }^{1}$ )

$\mathrm{Nb}$. of paternal MLGs (and corresponding maternal MLGs) 9 (9)

$\mathrm{Nb}$. of paternal specific alleles

Paternal clonal diversity

Genetic diversity among paternal MLGs

$\mathrm{Nb}$. of persistent paternal MLGs ${ }^{3}$

$\mathrm{Nb}$. of homozygous zygotes (\% of genotyped ones) ${ }^{4}$

$F_{\text {IS }}$ (and $p$-value) $)^{5}$

$\mathrm{Nb}$. of genotyped mycorrhizae (total $\mathrm{nb}$.)

$\mathrm{Nb}$. of vegetative MLGs found

$\mathrm{Nb}$. occurring as maternal/paternal MLGs ${ }^{3}$
0.14

$2 ; 1 ; 1$

$20(15)$

2

0.60

0.39

$1 ; 0 ; 0$

$10(7)$

0.5

0.15

0

$6(40 \%)$

$0.50\left(0^{*}\right)$

1 (12.5\%)

$0.68\left(0^{*}\right)$

$44(57)$

$4 / 0$
0.04

0.13

$1 ; 1 ;-$

23 (19)

$13(2)$

5

0.78

0.25

1 (2 seasons)

0

5 (26.3\%)

$0.30\left(0^{*}\right)$

14 (14)

2

$1 / 0$
5 (21.7\%)

$0.36\left(0^{*}\right)$

0.21

0.19

$0 ; 1 ;-$

$29(23)$

$15(4)$

14

0.63

0.35

$0.36\left(0^{*}\right)$
0.07

0.04

Succ

essf

$1 ;-$

ul

geno

typin

$\mathrm{g}$ for

inclu

sion

in

the

MLG

data

set,

see

crite

ria in

Mat

erial

and

Met

hods

Succ essf

amplification of the two mating types.

${ }^{3}$ MLGs with a significant $\mathrm{P}_{\text {sex }}$ only. 
${ }^{4}$ Parents with same SSR genotype, but different mating type.

${ }^{5}$ Test comparing the observed heterozygote deficit with that expected for random pairing of available parental and maternal MLGs of the brûlé (see Material and Methods; ${ }^{*}, \mathrm{P}<0.001$; this test could not be performed on PB3, which displays only two maternal MLGs).

Table 3. Genetic diversity on the two spontaneous truffle-grounds (SG1 and SG2) and two plantations (PG1 and PG2 ${ }^{1}$ ).

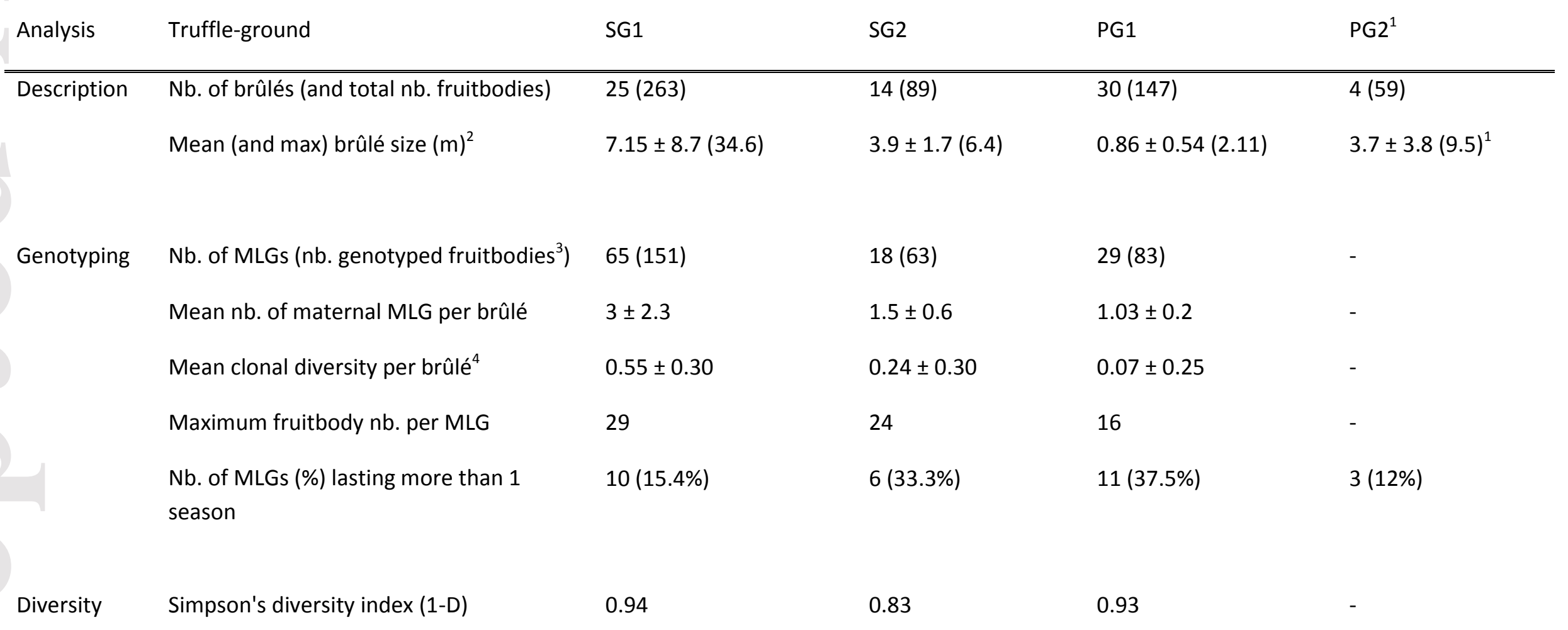


Evenness (ED)

Structure $0.03(p=0.62)$

${ }^{1}$ Data from Murat et al. (2013) that differ by some SSR loci used and a sampling restricted to the four most productive brûlés of the plantation were used for persistence and IBD analysis only.

${ }^{2}$ Approximated as the maximal distance between two fruitbodies from the same MLG and brûlé.

${ }^{3}$ Successful SSR genotyping for inclusion in the MLG dataset, see criteria in Materials and Methods.

${ }^{4}$ Calculated on brûlés with more than one fruitbody.

${ }^{5}$ Neighbourhood size by regression and likelihood methods, with $95 \%$ confidence intervals.

${ }^{6}$ Mantel test (with $p$-values) for the mating type, performed on culled MLG data set (see Materials and Methods) 


\section{Figure captions}

Figure 1. Tuber melanosporum life cycle, and questions addressed in this study (italics). Each haploid, vegetative mycelium is a self-sterile hermaphrodite capable of producing both male and female gametes (see Fig. S1 for illustrations). The various pending issues relate to the three main questions [1] to [3] addressed in the paper (see Introduction and Table 1), and an asterisk indicates the questions already addressed in previous studies, although exclusively from plantations or spontaneous truffle-grounds. IBD, isolation by distance.

Figure 2. MLGs identified from fruitbodies (a) and mycorrhizae (b) on spontaneous brûlé SB1. In (a), the harvesting season of each sampled fruitbody is indicated next to the circle corresponding to the maternal (larger circle with continuous outline) and paternal (smaller circle with dashed outline) MLGs. Maternal and paternal MLGs from the same fruitbody are superimposed. In (b), mycorrhizae were sampled in spring 2011 under each collected fruitbody from the previous season and from a fine-scale sampling in the two delineated zones. The filling colour of circles (maternal and paternal genets of fruitbody) and squares (mycorrhizal genets) encodes the MLG identity and the outline gives the mating type (red, MAT1-1; blue MAT1-2-1).

Figure 3. Isolation by distance analyses regressing genetic distance (â) to the logarithm of spatial distance (metres) on culled MLG data of spontaneous truffle-grounds SG1 (a) and SG2 (b) and of planted truffle-grounds PG1 (c) and PG2 (d), with respective neighbourhood size of 21.9; 11.2; 26.4; 6 (calculated as $1 / \mathrm{b}$; where $b$ is the slope of the regression).

Figure 4. Isolation by distance analyses regressing genetic distance (â) to the logarithm of spatial distance (meters) at the regional scale. IBD was assessed separately within fruitbodies from the spontaneous and planted compartments (respectively, the green and blue dots), between fruitbodies of the two compartments (yellow dots) and over all fruitbodies (black linear regression), with detailed neighbourhood size (calculated as $1 / b$; where $b$ is the slope of the regression) and $95 \%$ confidence interval.

\section{Supporting Information:}

Table S1 - SSR loci characteristics and selection for data analyses.

Table S2 - MLG details (persistence, size) with probabilities $\left(\mathrm{P}_{\text {sex }}\right.$ and $\left.\mathrm{P}_{\text {Gen }}\right)$ at the brûlé scale.

Table S3 - MLG details (persistence, size) with probabilities $\left(\mathrm{P}_{\text {sex }}\right.$ and $\left.\mathrm{P}_{\text {Gen }}\right)$ at the truffle-ground scale.

Table S4 - Multilocus linkage disequilibrium at the truffle-ground scale. 
Fig. S1 - An illustrated life cycle of Tuber melanosporum.

Fig. S2 - Map of the sampling site within Languedoc-Roussillon region (France).

Fig. S3 - Maps of fruitbodies and MLGs from mycorrhizae on planted brûlés (PB1, PB2, PB3).

Fig. S4 - Maps of fruitbody MLGs (including fruiting seasons), MAT and MAT on culled MLG data on each studied truffle-ground (SG1; SG2; PG1; PG2).

Fig. S5 - Principal Component Analysis on multilocus genotypes of the regional data set.

Fig. S6 - Updated Tuber melanosporum life cycle (modified from Fig. 1), including the current findings.

Figure 1. Tuber melanosporum life cycle, and questions addressed in this study (italics). Each haploid, vegetative mycelium is a selfsterile hermaphrodite capable of producing both male and female gametes (see Fig. S1 for illustrations). The various pending issues relate to the three main questions [1] to [3] addressed in the paper (see Introduction and Table 1), and an asterisk indicates the questions already addressed in previous studies, although exclusively from plantations or spontaneous truffle-grounds. IBD, isolation by distance.

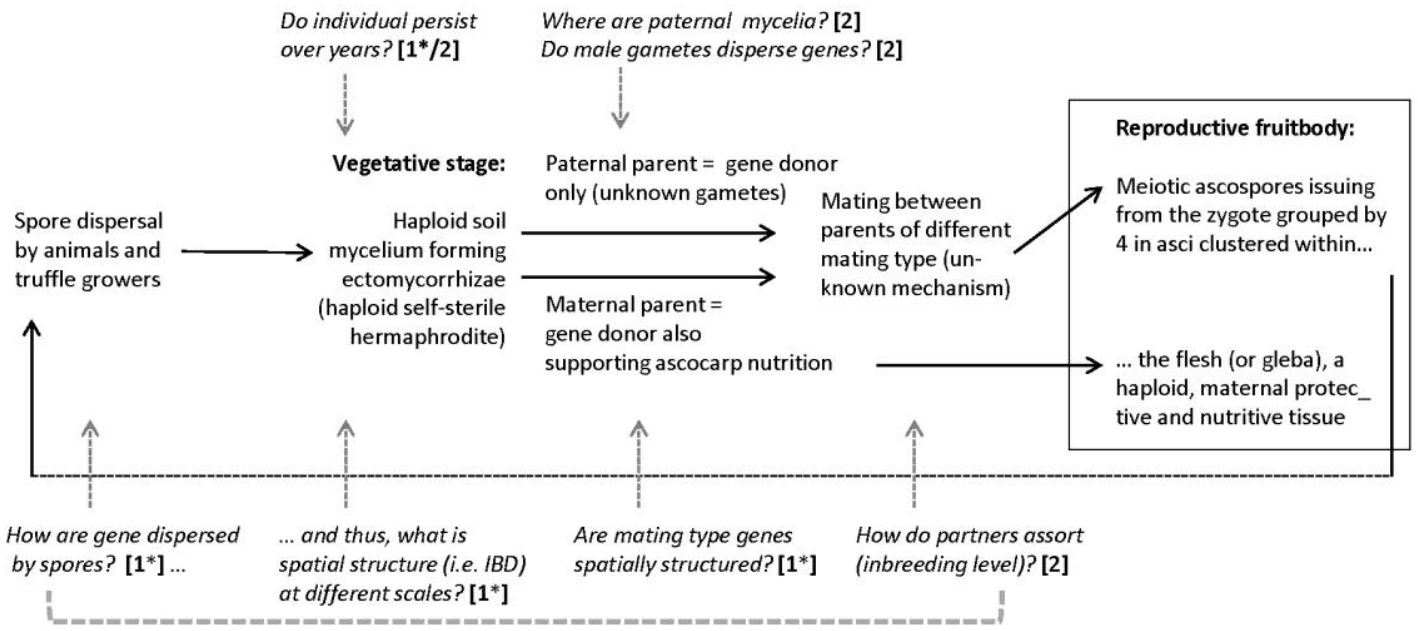

Do these genetic features differ in plantations versus spontaneous truffle grounds? [3]

Do planted and spontaneous compartments exchange genes? [3] 
a

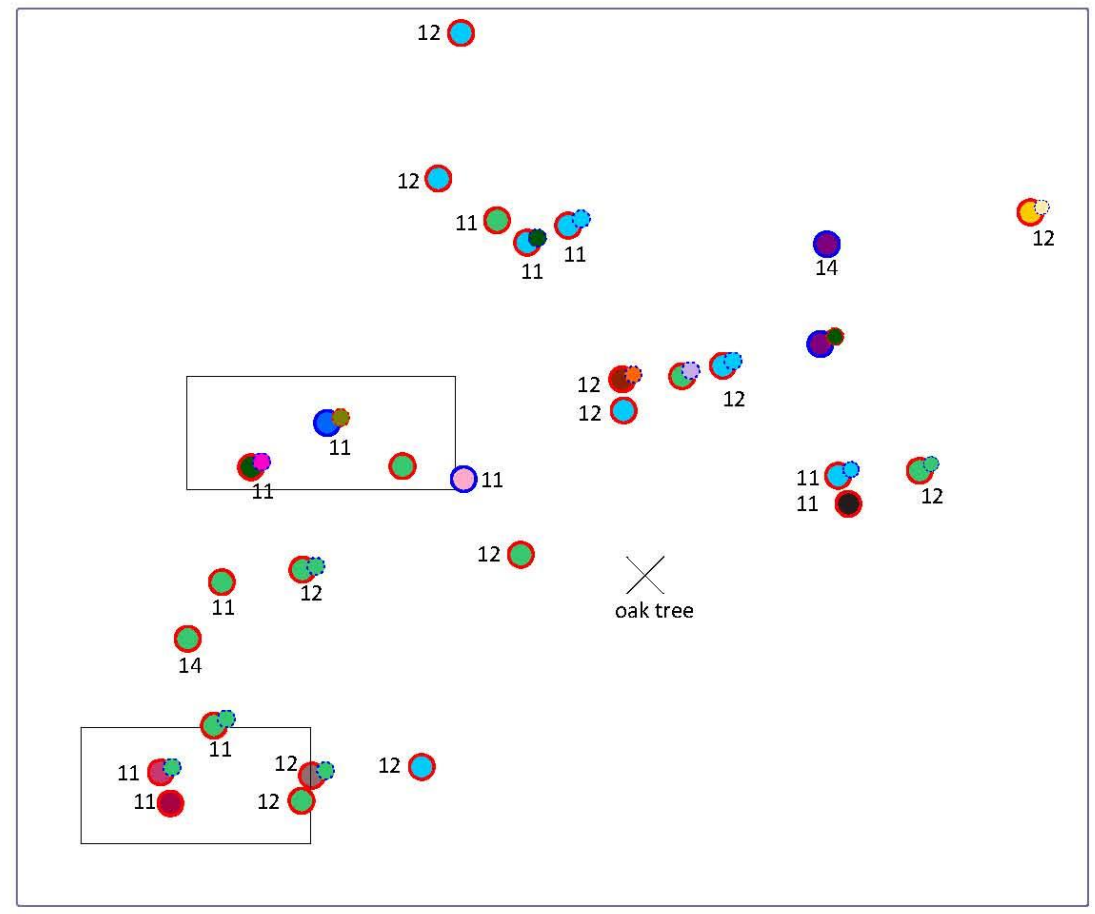

b

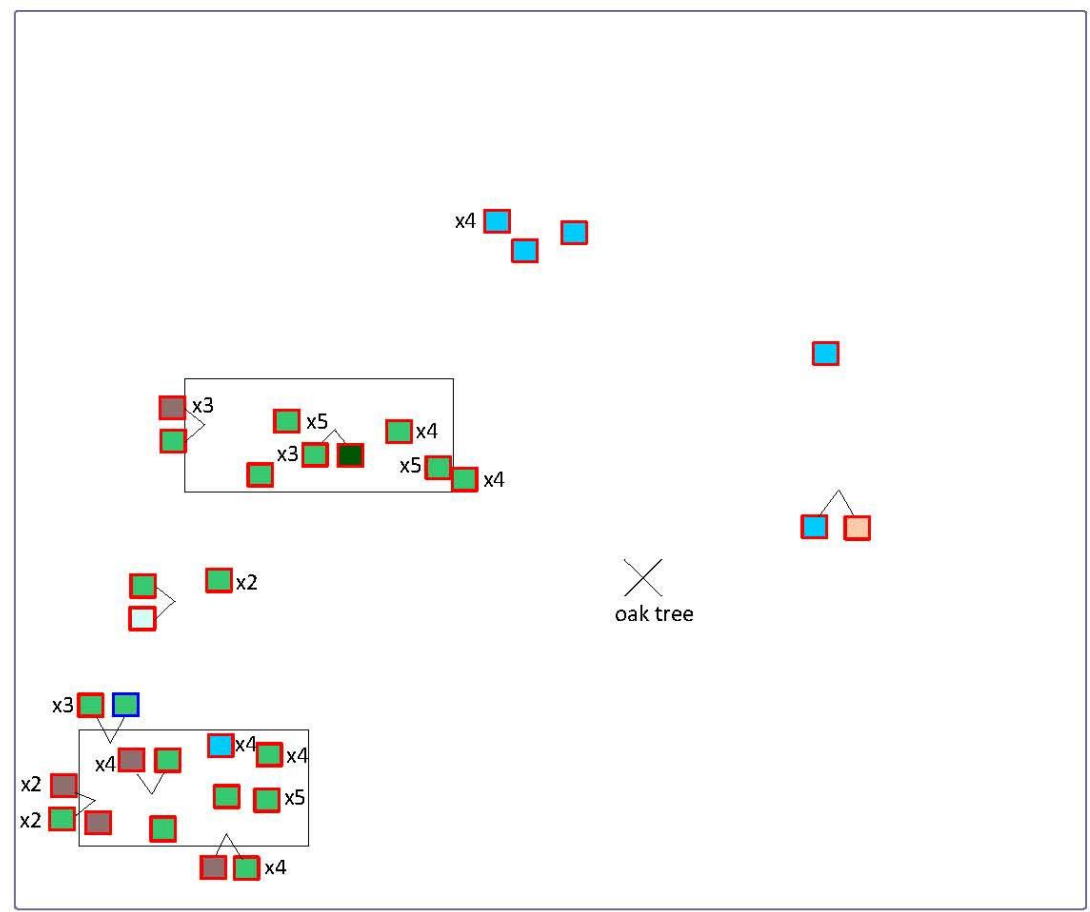

Sample genotypes

Maternal

$\because$ Paternal

C Forming one fruitbody

Mycorrhizae

MLGs

$1 \bigcirc 12$

$\mathrm{O}_{2} \bigcirc 13$

$\mathrm{O}^{3} \bigcirc 14$

${ }_{4} \bigcirc 15$

$\mathrm{O}^{\circ} \bigcirc 16$

○ 17

$\mathrm{O}_{7} \bigcirc 18$

$\mathrm{O}_{8} \bigcirc 19$

$\bigcirc \bigcirc 20$

$10 \bigcirc 21$

$11 \bigcirc 22$

Mating type

O1-1

1-2-1

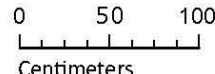

Centimeters

Figure 2. MLGs identified from fruitbodies (a) and mycorrhizae (b) on spontaneous brûlé SB1. In (a), the harvesting season of each sampled fruitbody is indicated next to the circle corresponding to the maternal (larger circle with continuous outline) and paternal (smaller circle with dashed outline) MLGs. Maternal and paternal MLGs from the same fruitbody are superimposed. In (b), mycorrhizae were sampled in spring 2011 under each collected fruitbody from the previous season and from a fine-scale sampling in the two delineated zones. The filling colour of circles (maternal and paternal genets of fruitbody) and squares (mycorrhizal genets) encodes the MLG identity and the outline gives the mating type (red, MAT 1-1; blue MAT 1-2-1). 
a.

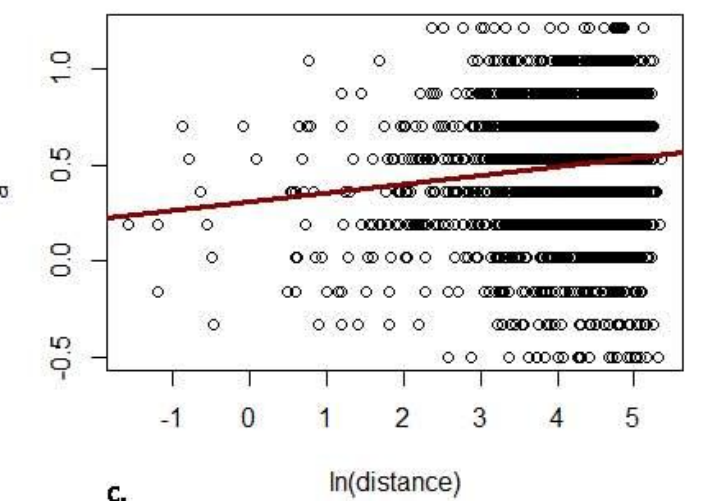

c.

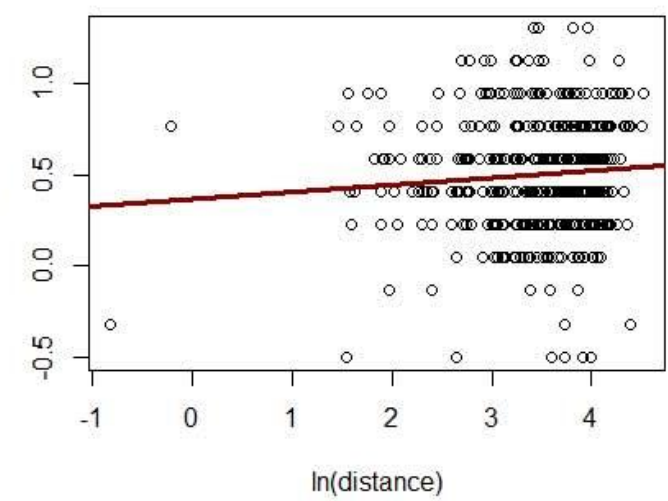

b.

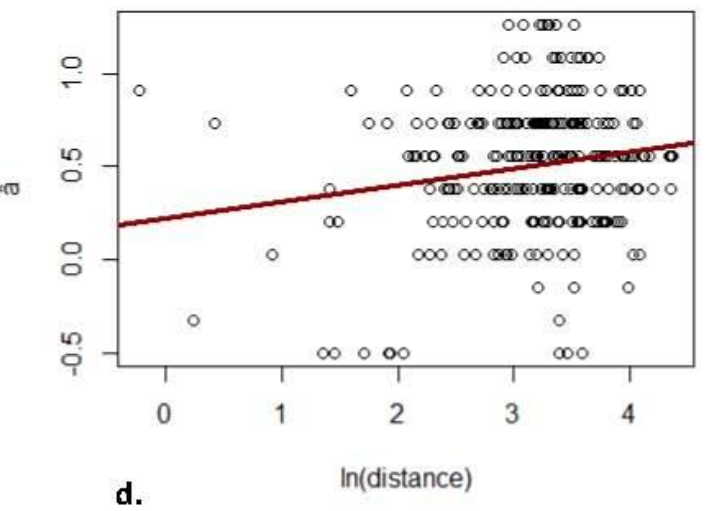

d.

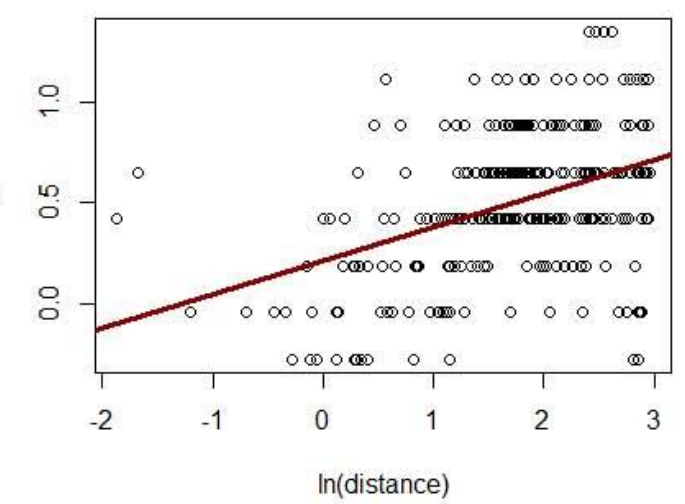

Figure 3. Isolation by distance analyses regressing genetic distance (â) to the logarithm of spatial distance (metres) on culled MLG data of spontaneous truffle-grounds SG1 (a) and SG2 (b) and of planted trufflegrounds PG1 (c) and PG2 (d), with respective neighbourhood size of $21.9 ; 11.2 ; 26.4 ; 6$ (calculated as $1 / \mathrm{b}$; where $b$ is the slope of the regression). 


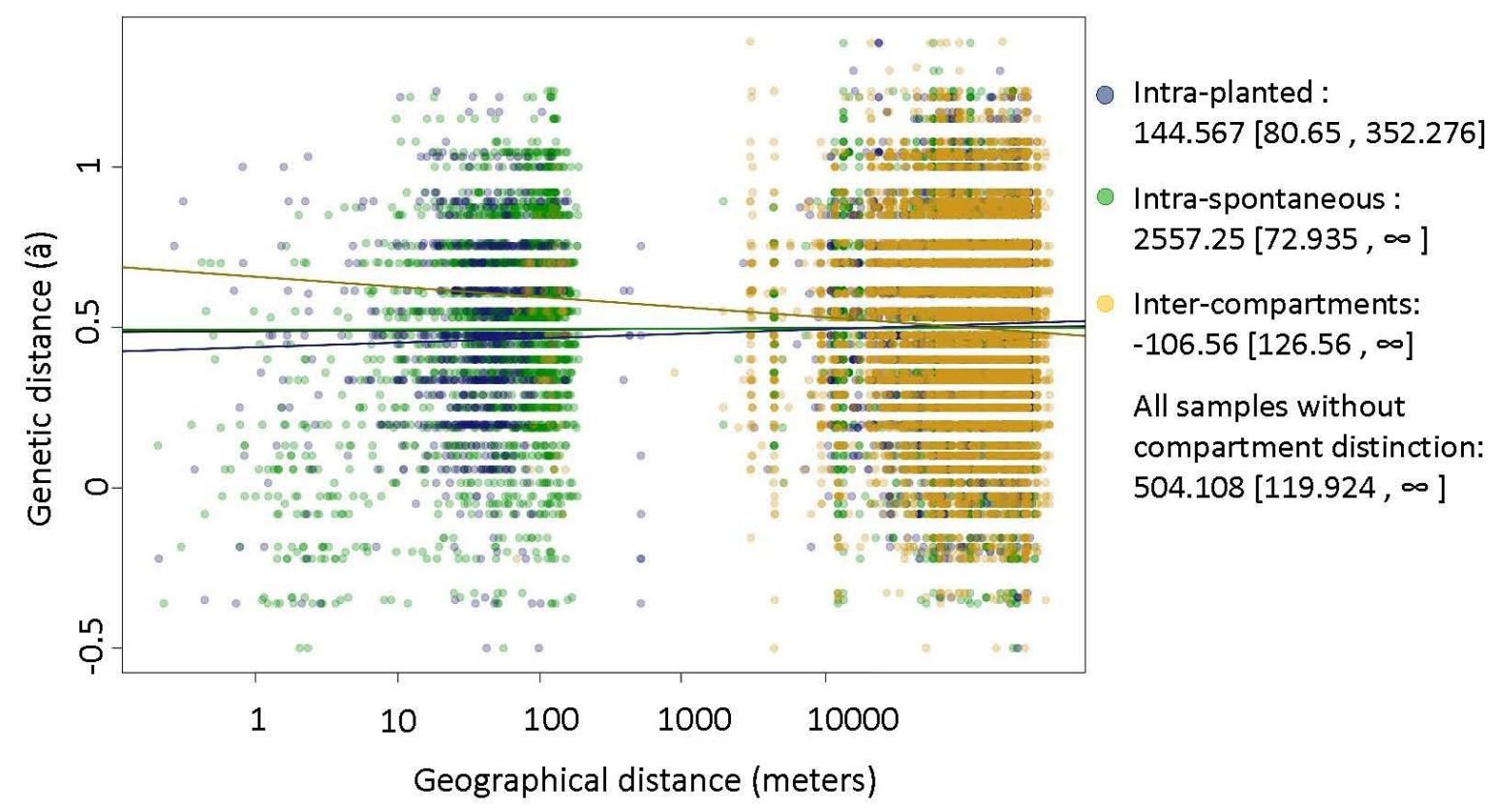

Figure 4. Isolation by distance analyses regressing genetic distance (â) to the logarithm of spatial distance (meters) at the regional scale. IBD was assessed separately within fruitbodies from the spontaneous and planted compartments (respectively, the green and blue dots), between fruitbodies of the two compartments (yellow dots) and over all fruitbodies (black linear regression), with detailed neighbourhood size (calculated as $1 / \mathrm{b}$; where $b$ is the slope of the regression) and $95 \%$ confidence interval. 